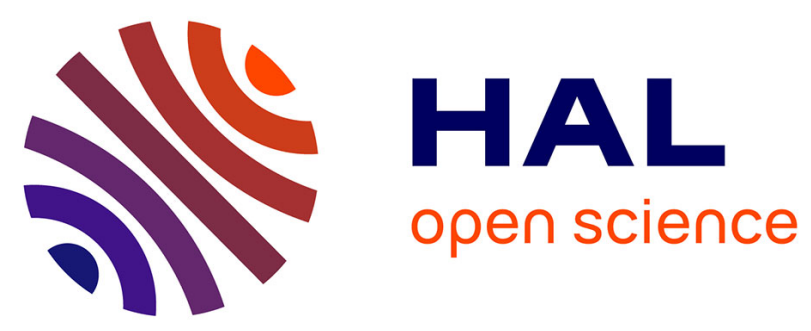

\title{
Unraveling the Speciation of $\beta$-Amyloid Peptides during the Aggregation Process by Taylor Dispersion Analysis
}

Mihai Deleanu, Jean-François Hernandez, Luca Cipelletti, Jean-Philippe Biron, Emilie Rossi, Myriam Taverna, Herve Cottet, Joseph Chamieh

\section{- To cite this version:}

Mihai Deleanu, Jean-François Hernandez, Luca Cipelletti, Jean-Philippe Biron, Emilie Rossi, et al.. Unraveling the Speciation of $\beta$-Amyloid Peptides during the Aggregation Process by Taylor Dispersion Analysis. Analytical Chemistry, 2021, 93 (16), pp.6523-6533. 10.1021/acs.analchem.1c00527 . hal03359470

\author{
HAL Id: hal-03359470 \\ https://hal.science/hal-03359470
}

Submitted on 30 Sep 2021

HAL is a multi-disciplinary open access archive for the deposit and dissemination of scientific research documents, whether they are published or not. The documents may come from teaching and research institutions in France or abroad, or from public or private research centers.
L'archive ouverte pluridisciplinaire HAL, est destinée au dépôt et à la diffusion de documents scientifiques de niveau recherche, publiés ou non, émanant des établissements d'enseignement et de recherche français ou étrangers, des laboratoires publics ou privés. 
2 during the aggregation process by Taylor dispersion

4 Mihai Deleanu ${ }^{1}$, Jean-François Hernandez ${ }^{1}$, Luca Cipelletti ${ }^{2,3}$, Jean-Philippe Biron ${ }^{1}$, Emilie

5 Rossi ${ }^{4}$, Myriam Taverna ${ }^{4}$, Hervé Cottet $^{* 1}$, Joseph Chamieh $^{* 1}$

$6 \quad{ }^{1}$ IBMM, Université Montpellier, CNRS, ENSCM, 34095 Montpellier, France

$7 \quad{ }^{2}$ Laboratoire Charles Coulomb (L2C), Université Montpellier, CNRS, Montpellier, France.

$8 \quad{ }^{3}$ Institut Universitaire de France (IUF), France

9 22Université Paris-Saclay, CNRS, Institut Galien Paris-Saclay, 92296, Châtenay-Malabry, France

$11 *$ CORRESPONDING AUTHOR

12 Tel: +33 46714 3920, Fax: +33 46763 1046. E-mail: joseph.chamieh@umontpellier.fr

13 Tel: +33 46714 3427, Fax: +33 46763 1046. E-mail: herve.cottet@umontpellier.fr

14

15 


\section{ABSTRACT}

17 The aggregation mechanisms of amyloid $\beta$ peptides depend on multiple intrinsic and extrinsic 18 physico-chemical factors (e.g. peptide chain length, truncations, peptide concentration, $\mathrm{pH}$, ionic 19 strength, temperature, metal concentrations...). Due to this high number of parameters, the

20 formation of the oligomers and their propensity to aggregate make the elucidation of this 21 physiopathological mechanism a challenging task. From the analytical point of view, up to our

22 knowledge, few techniques are able to quantify, in real time, the proportion and the size of the

23 different soluble species during the aggregation process. This work aims at demonstrating the 24 interest of modern Taylor dispersion analysis (TDA) performed in capillaries (50 $\mu \mathrm{m}$ i.d.) to 25 unravel the speciation of $\beta$-amyloid peptides in low volume peptide samples $(\sim 100 \mu \mathrm{L})$ with an 26 analysis time of $\sim 3$ min per run. TDA was applied to study the aggregation process of $A \beta(1-40)$

27 and $\mathrm{A} \beta(1-42)$ peptides at physiological $\mathrm{pH}$ and temperature, where more than 140 data points 28 were generated with a total volume of $\sim 1 \mu \mathrm{L}$ over the whole aggregation study (about $0.5 \mu \mathrm{g}$ of 29 peptide). TDA was able the give a complete and quantitative picture of the $\mathrm{A} \beta$ speciation during 30 the aggregation process, including the sizing of the oligomers and protofibrils, the consumption 31 of the monomer, and the quantification of different early and late-formed aggregated species.

33 KEYWORDS. Taylor dispersion analysis; peptide aggregation; oligomers; amyloid beta 34 peptides; diffusion coefficient; hydrodynamic radius. 


\section{Introduction}

38 Alzheimer's disease (AD) is the result of a slow degeneration of neurons. It starts in the

39 hippocampus (which lies in the medial temporal lobes of the brain and is responsible for the

40 long-term memory) then extends to the rest of the brain. This fatal neurodegenerative disorder is

41 characterized by progressive cognitive and functional impairment and memory $\operatorname{loss}^{1}$. Up till

42 today, there is no cure for $\mathrm{AD}$, however, there is extensive research to reveal its risk factors and

43 the mechanisms leading to this dementia. Indeed, more than 95000 articles including more than

4419000 reviews dealing with Alzheimer's disease were published just in the last decade (number

45 of articles obtained on PubMed between 2010 and 2020 by searching "Alzheimer's disease").

46 For many years, AD was thought to be mainly associated to the formation of extracellular

47 senile plaques composed primarily of amyloid $\beta$ peptides $(A \beta)$ and hyperphosphorylated

48 neurofibrillary tangles of tau protein ${ }^{2}$. Consequently, research toward AD curative treatments has

49 been driven largely by the amyloid cascade hypothesis. This hypothesis developed in the 1990's,

50 relies on the fact that the most hydrophobic $\mathrm{A} \beta$ peptides (A $\beta 1-40$ and mainly $\mathrm{A} \beta 1-42)$ released

51 by APP (Amyloid- $\beta$ Precursor Protein) enzymatic cleavage, readily self-assemble to form

52 amyloid species with evolving morphology and size (oligomers of increasing size, protofibrils

53 and then fibrils) through a highly complicated process, finally accumulating into plaques which

54 were believed to be the major pathogenic forms of $A \beta^{3,4}$. More recently, production of soluble

55 amyloid- $\beta$ oligomers $^{5}$ and inflammation $^{6}$ have also emerged as important early steps in the

56 pathogenesis of Alzheimer's disease. The "amyloid- $\beta$ oligomer hypothesis", which is still

57 under debate, states that the main reasons behind $\mathrm{AD}$ is the formation of soluble oligomers of $\mathrm{A} \beta$

$58{ }^{7-10}$ considered to be more toxic than plaques and causing selective nerve cell death ${ }^{10-12}$. Indeed,

59 soluble $A \beta$ oligomers $(\mathrm{A} \beta \mathrm{O})$ are believed to be more toxic ${ }^{13}$ than fibrils, which precipitate as 
60 plaques, because they are able to spread across neuronal tissue and they are supposed to mediate

61 neurotoxicity and synaptic loss through binding to membrane receptors, including the prion

62 protein $^{14,15}$. To assess its validity and to develop new drug candidates against AD targeting the

63 soluble oligomers, new analytical methodologies able to finely monitor, quantify and

64 characterize these oligomeric species are required. However, in contrast to fibrils, which have

65 low solubility and are highly stable, the soluble oligomers are fragile, metastable, $\operatorname{transient}^{16}$,

66 highly polydisperse in size, and therefore more difficult to detect and study in real time ${ }^{16}$.

67 When studied in vitro, the aggregation mechanisms leading to the oligomers and then to fibrils

68 depend on multiple physico-chemical factors, that can be intrinsic ${ }^{17}$ (e.g. chain length,

69 truncations, net charge, hydrophobicity) and extrinsic, such as concentration ${ }^{18,19}, \mathrm{pH}^{\text {, }}$

70 temperature, incubation conditions ${ }^{20}$, buffer ionic strength and salt composition ${ }^{21}$. The influence

71 of metals and other proteins has also been reported. ${ }^{10}$ Due to this high number of parameters the

72 elucidation of the aggregation mechanism is a challenging task. The detection of fibrils during

73 the early stages of the aggregation process can be realized by multiple analytical techniques, and

74 specifically by fluorescence using the ThT assay ${ }^{22}$. However, the ThT assay is mainly insensitive

75 to $\mathrm{A} \beta$ oligomeric species ${ }^{23}$. In contrast, other analytical techniques are able to detect the presence

76 of oligomers such as size exclusion chromatography (SEC) ${ }^{24,25}$, AFM microscopy ${ }^{26,27}$, capillary

77 electrophoresis ${ }^{28}$, mass spectrometry ${ }^{29-31}$, and dynamic light scattering (DLS) ${ }^{32}$, to name a few.

78 However, some of the aforementioned methods require large sample volume (e.g. SEC), others

79 are very sensitive to the presence of the large fibrils (or particles) making the detection of the

80 small oligomers a difficult task (e.g. DLS). Few of these methods are able to follow in real time

81 the aggregation process in a medium representative of the in vivo conditions. Furthermore, some

82 of these techniques require a sample pretreatment before the analysis ${ }^{25}$, which may alter the form 
83 of the species present in the sample. Thus, new methods able to rapidly determine the size of

84 aggregates in the range $1-100 \mathrm{~nm}$ are highly required to better understand the real-time 85 mechanism of oligomer formation.

86 In this context, Taylor Dispersion Analysis ${ }^{33-35}$ (TDA) appears as a very promising alternative

87 analytical method. Indeed, TDA is an absolute method (no calibration needed) allowing for the

88 determination of the molecular diffusion coefficient, $D$, and of the hydrodynamic radius, $R_{h}$, of a

89 solute, including for mixtures, without any bias in size, the contribution of the small and the

90 large solutes being proportional to their mass abundance in the mixture ${ }^{36}$. TDA is based on the

91 dispersion of an injected band under a laminar Poiseuille flow. Its implementation in narrow bore

92 capillaries (typically $\sim 50 \mu \mathrm{m}$ i.d.) presents several advantages ${ }^{37-40}$ such as a low sample

93 consumption, a short analysis time, a wide range of sizing (from angstrom to sub-micron) and a

94 straightforward analysis without any sample pretreatment or filtration ${ }^{41-43}$.

95 In this work, TDA was applied to study the aggregation process of two A $\beta$ isoforms $A \beta(1-40)$

96 and $\mathrm{A} \beta(1-42)$ at physiological $\mathrm{pH}(7.4)$ and temperature $\left(37^{\circ} \mathrm{C}\right)$ by providing a direct

97 determination of all possible forms of $A \beta$ amyloid according to the incubation time. TDA was

98 able to provide a complete picture of the $\mathrm{A} \beta$ speciation during the in-vitro aggregation process,

99 including the consumption of the monomer and the formation of oligomers, protofibrils and 100 fibrils.

\section{Materials and methods}

\section{Materials}

103 Synthesized Amyloid beta (1-40) (denoted $A \beta(1-40)$ in this work) was prepared as described in 104 the Solid-phase synthesis of $A \beta(1-40)$ section in the supporting information (Figure SI.1 shows a 
105 scheme of the synthesis protocol, while Figure SI.2 shows the chromatographic and mass

106 spectrometry analysis of the synthesized peptide). Commercial Amyloid beta 1-40 (batch number

107 1658309, >95\%) (denoted $\mathrm{cA} \beta(1-40)$ in this work) was purchased from Anaspec (USA).

108 Amyloid beta (1-42) (A $\beta(1-42)$, batch number 1071428, >95\%) was purchased from Bachem

109 (Bubendorf, Switzerland). Thioflavin T, sodium dihydrogen phosphate,

110 tris(hydroxymethyl)aminomethane, hydrochloric acid fuming 37\%, sodium chloride and sodium

111 hydroxide were purchased from Sigma Aldrich (France). Fmoc protected amino acids, coupling

112 reagents HATU (Hexafluorophosphate Azabenzotriazole Tetramethyl Uronium) and PyBOP

113 (benzotriazol-1-yl-oxytripyrrolidinophosphonium hexafluorophosphate) were purchased from

114 Iris Biotech (Germany). The ChemMatrix H-Val-O-Wang resin was purchased from PCAS

115 Biomatrix (Canada). Dimethylformamide, acetic anhydride, piperidine, dichloromethane,

116 methanol, acetonitrile, trifluoroacetic acid and diethyl ether were acquired from Carlo Erba

117 (Italy), Sigma-Aldrich (Merck, Germany), Acros Organics (Thermo Fisher-Scientific, Germany)

118 or Honeywell-Riedel de Haën (Fisher-Scientific, Illkirch, France), and were all of analytical

119 grade. $N, N$-diisopropylethylamine, 1,1,1,3,3,3-hexafluoro-2-propanol, triisopropylsilane (TIS)

120 and tetra- $n$-butylammonium bromide were purchased from Alfa Aesar (Thermo Fisher-

121 Scientific, Germany) or Fluorochem (UK). The ultrapure water used for all buffers was prepared

122 with a MilliQ system from Millipore (France).

\section{Peptide pretreatment}

124 Both $A \beta(1-40)$ and $A \beta(1-42)$ were first pretreated independently as described elsewhere ${ }^{28,44}$.

125 Briefly, $A \beta(1-40)$ and $A \beta(1-42)$ were dissolved in a $0.10 \%(\mathrm{~m} / \mathrm{v})$ and $0.16 \%(\mathrm{~m} / \mathrm{v}) \mathrm{NH}_{4} \mathrm{OH}$

126 aqueous solution respectively to reach a final peptide concentration of $2 \mathrm{mg} / \mathrm{mL}$. The peptide

127 solutions were then incubated at room temperature for $10 \mathrm{~min}$, separated into several aliquots 
128 and freeze-dried. The aliquot volume was calculated in order to obtain $10 \mathrm{nmol}$ of peptide in

129 each Eppendorf tube. The lyophilized peptide aliquots were stored at $-20{ }^{\circ} \mathrm{C}$ until further use.

ThT fluorescence assay

131 In order to check the initial state of aggregation of the studied peptides, ThT fluorescence assay

132 was used by adapting the protocol described in ${ }^{45}$. Briefly, peptides were dissolved at a 133 concentration of $1 \mathrm{mM}$ in a $1 \% \mathrm{NH}_{4} \mathrm{OH}$ aqueous solution, then diluted with $10 \mathrm{mM}$ Tris- $\mathrm{HCl}+$ $134100 \mathrm{mM} \mathrm{NaCl}$ buffer $(\mathrm{pH} 7.4)$ to a final concentration of $0.2 \mathrm{mM}$. A volume of $10 \mu \mathrm{L}$ of the 135 latter peptide solution was withdrawn and put in a Costar® 96-well black polystyrene plate along 136 with $189 \mu \mathrm{L}$ of $40 \mu \mathrm{M}$ ThT in the Tris-HCl saline buffer solution. The fluorescence was 137 monitored at room temperature for $24 \mathrm{~h}$ using a Berthold TriStar LB 941 instrument (Germany) 138 (excitation wavelength $430 \mathrm{~nm}$ and emission wavelength $485 \mathrm{~nm}$ ). Control wells were prepared 139 by replacing the $10 \mu \mathrm{L}$ of peptide solution with $10 \mu \mathrm{L}$ of a $0.2 \% \mathrm{NH}_{4} \mathrm{OH}$ aqueous solution 140 prepared by diluting a $1 \% \mathrm{NH}_{4} \mathrm{OH}$ aqueous solution with $10 \mathrm{mM}$ Tris- $\mathrm{HCl}+100 \mathrm{mM} \mathrm{NaCl}$ 141 buffer ( $\mathrm{pH}$ 7.4). Five wells were prepared for each solution.

\section{Peptide aggregation study by Taylor dispersion analysis}

143 TDA was performed on an Agilent 7100 (Waldbronn, Germany) capillary electrophoresis system 144 using bare fused silica capillaries (Polymicro technologies, USA) having $40 \mathrm{~cm} \times 50 \mu \mathrm{m}$ i.d. 145 dimensions and a detection window at $31.5 \mathrm{~cm}$. New capillaries were conditioned with the 146 following flushes: $1 \mathrm{M} \mathrm{NaOH}$ for $30 \mathrm{~min}$; ultrapure water for $30 \mathrm{~min}$. Between each analysis, 147 capillaries were rinsed with $20 \mathrm{mM}$ phosphate buffer, $\mathrm{pH} 7.4$ (2 min). Samples were injected 148 hydrodynamically on the inlet end of the capillary (44 mbar, $3 \mathrm{~s}$, injected volume is about $7 \mathrm{~nL}$ 149 corresponding to $1 \%$ of the capillary volume to the detection point). Experiments were 150 performed using a mobilization pressure of 100 mbar. The temperature of the capillary cartridge 
151 was set at $37^{\circ} \mathrm{C}$. The vial carrousel was thermostated using an external circulating water bath

152 from Bioblock (France). The solutes were monitored by UV absorbance at $191 \mathrm{~nm}$. The mobile

153 phase was a $20 \mathrm{mM}$ phosphate buffer, $\mathrm{pH} 7.4$ (viscosity at $37^{\circ} \mathrm{C}$ is $\left.0.7 \times 10^{-4} \mathrm{~Pa}_{\mathrm{s}}\right)^{28}$. Peptide

154 samples were dissolved in $100 \mu \mathrm{L}$ of $20 \mathrm{mM}$ phosphate buffer, $\mathrm{pH} 7.4$, to reach a final

155 concentration of $100 \mu \mathrm{M}$ and were immediately transferred to a vial and incubated at $37^{\circ} \mathrm{C}$ in the

156 capillary electrophoresis instrument's carrousel. The aggregation was conducted by injecting the

157 sample $\left(V_{i n j} \approx 7 \mathrm{~nL}\right)$ every $7 \mathrm{~min}$ in the case of $\mathrm{A} \beta(1-42)$ and each $30 \mathrm{~min}$ in the case of $\mathrm{A} \beta(1-$

158 40). The total number of TDA runs for each sample was about 150, corresponding to a total

159 sample volume of $1050 \mathrm{~nL}(1.05 \mu \mathrm{L})$. To avoid sample evaporation, the vial cap was changed

160 three times a day. The taylorgrams were recorded with the Agilent Chemstation software then

161 exported to Microsoft Excel for subsequent data processing.

\section{Dynamic light scattering}

163 Complementary Dynamic Light Scattering data were acquired using a standard setup by

164 Brookhaven Instruments Co. (BI-900AT), equipped with a $150 \mathrm{~mW}$ laser with in-vacuo 165 wavelength $\lambda=535 \mathrm{~nm}$. Frozen, dehydrated samples were thawed at room temperature. At time $166 t_{a g}=0$, a volume of $100 \mu \mathrm{L}$ of $20 \mathrm{mM}$ phosphate buffer, $\mathrm{pH} 7.4$, filtered through a $0.22 \mu \mathrm{m}$

167 Millipore filter was added to the thawed powder, setting the $\mathrm{A} \beta 42$ concentration to $100 \mu \mathrm{M}$. The 168 sample was injected in an NMR tube and placed in the setup immediately after mixing.

169 Measurements were performed as a function of $t_{a g}$ by alternating runs at scattering angles $\theta=90^{\circ}$ 170 and $\theta=45^{\circ}$ (run duration: $240 \mathrm{~s}$ and $360 \mathrm{~s}$, respectively). The sample was thermostated at $37.0 \pm$ $1710.1{ }^{\circ} \mathrm{C}$

172 The CONTIN algorithm ${ }^{46,47}$ embedded in the Brookhaven software was used to extract $P_{I}(D)$, the 173 intensity-weighted distribution of the diffusion coefficients $D$ of the scatterers, which was then 
174 converted to the mass-weighted distribution of hydrodynamic radii $R_{h}, P_{M}\left(R_{h}\right)$, using custom

175 software. In performing the conversion, it was assumed that the peptides aggregate by forming

176 cylindrical structures resulting from the stacking of dimer units (see the discussion section and

177 Figure 6). This allowed us to calculate the mass and scattered intensity (to within an inessential 178 multiplicative constant) of the aggregates, as a function of their hydrodynamic radius, obtained

179 via the HYDROPRO software ${ }^{48}$. Knowledge of $M\left(R_{h}\right)$ and $I\left(R_{h}\right)$ allowed for re-expressing $180 P_{I}(D)$ as $P_{M}\left(R_{h}\right)$, using standard probability distribution transformation laws and the Stokes-

181 Einstein relationship $R_{h}=k_{b} T /(6 \pi \eta D)$, with $k_{b}$ Boltzmann's constant, $T=310.15 \mathrm{~K}$, and $\eta=0.7$

$182 \mathrm{mPa}$ s the solvent viscosity.

\section{Results and discussion}

\section{ThT assay and the initial state of the peptide samples}

185 The aggregation of $A \beta$ peptides is a highly complex process that is dependent on, and very 186 sensitive to, the initial conditions of the peptides preparation. The initial presence of aggregates 187 (or seeds of aggregates) can drastically influence the aggregation process. Therefore, the peptides

188 were treated upon reception with an ammonium hydroxide solution before freeze drying and 189 storage $^{28}$. The aim of this step is to dissociate any aggregated peptide and to start the kinetic 190 studies from the very early steps, with a non-aggregated sample. To confirm the success of this 191 step, samples were submitted to the ThT fluorescence assay ${ }^{49}$. Figure SI.3 shows the

192 fluorescence kinetic curves of the studied peptide batches: the synthesized $A \beta(1-40)$, the 193 commercial cA $\beta(1-40), \mathrm{A} \beta(1-42)$ and a control run. Only the commercial $\mathrm{cA} \beta(1-40)$ was found 194 to be initially aggregated, despite the ammonium hydroxide treatment, since it showed an initial 195 relatively high fluorescence signal and nearly no lag phase. In contrast, the synthesized $A \beta(1-40)$ 
196 and the commercial $A \beta(1-42)$ peptides were assumed to be free of aggregates since their initial

197 fluorescence intensity was low and in the same order of magnitude as the control run. These

198 results show the importance of using clean (non-aggregated) samples for kinetic studies.

\section{Processing of the taylorgrams}

200 Briefly, the band broadening resulting from Taylor dispersion is easily quantified via the 201 temporal variance $\left(\sigma^{2}\right)$ of the elution profile. For that, a fit of the experimental peak with a

202 Gaussian function allows for the determination of $\sigma^{2}$ and the calculation of the molecular

203 diffusion coefficient, $D$, and consequently the hydrodynamic radius, $R_{h}$. The reader may refer to 204 the supporting information for the theoretical aspects, equations and more details on the data 205 processing.

206 The peptides were incubated at $37^{\circ} \mathrm{C}$ in a $20 \mathrm{mM}$ phosphate buffer at $\mathrm{pH} 7.4$. The aggregation 207 was followed for $72 \mathrm{~h}$ and $12.5 \mathrm{~h}$ for $A \beta(1-40)$ and $A \beta(1-42)$, respectively. Figure 1 shows the 208 taylorgrams recorded at selected incubation times for $\mathrm{A} \beta(1-40)$ (Figure 1A) and $\mathrm{A} \beta(1-42$ )

209 (Figure 1B) while all experimental taylorgrams, for all incubations times $t_{a g}$, are shown in 210 Figures SI.4 and SI.5. Importantly, the elution profile evolved faster in the case of A $\beta(1-42)$ as 211 compared to $A \beta(1-40)$, suggesting a faster aggregation kinetics for this peptide. A second 212 observation is that, for both studied peptides, the main peak observed at an elution time $t_{0} \approx 2$

213 min, which represents the $\mathrm{A} \beta$ monomer at $t_{a g}=0$, tended to broaden and to decrease in intensity 214 during the aggregation process. This indicates the appearance of larger species and the decrease 215 in concentration of the soluble species in the sample. At the end of the aggregation experiment, 216 only a small sharp peak was observed (with a size corresponding to a small molecule/ion of 217 about $0.4 \mathrm{~nm}$, smaller than the size of the peptide monomer $\sim 1.8 \mathrm{~nm}$ ), indicating the 
218 disappearance of the soluble peptides, probably transformed into insoluble and larger aggregates

219 that were not entering in the capillary, leading to the decrease in the peak area. At intermediate

220 incubation times (e.g. $t_{a g}$ between $0.5 \mathrm{~h}$ and $\sim 11 \mathrm{~h}$ for $\mathrm{A} \beta(1-42)$ ) the left side of the elution

221 profile displayed spikes (very sharp peaks appearing before the main elution peak at elution

222 times between 0.9 and $1.7 \mathrm{~min}$ ), demonstrating the presence of very large species that are out of

223 the Taylor regime ${ }^{50,51}$ and rather belong to the so-called convective regime. In addition to the

224 convective regime ${ }^{50}$, large aggregates such as $\mathrm{A} \beta$ fibrils can also generate spikes, as seen in

225 capillary electrophoresis and/or hydrodynamic flow of bacterial aggregates ${ }^{52}$.
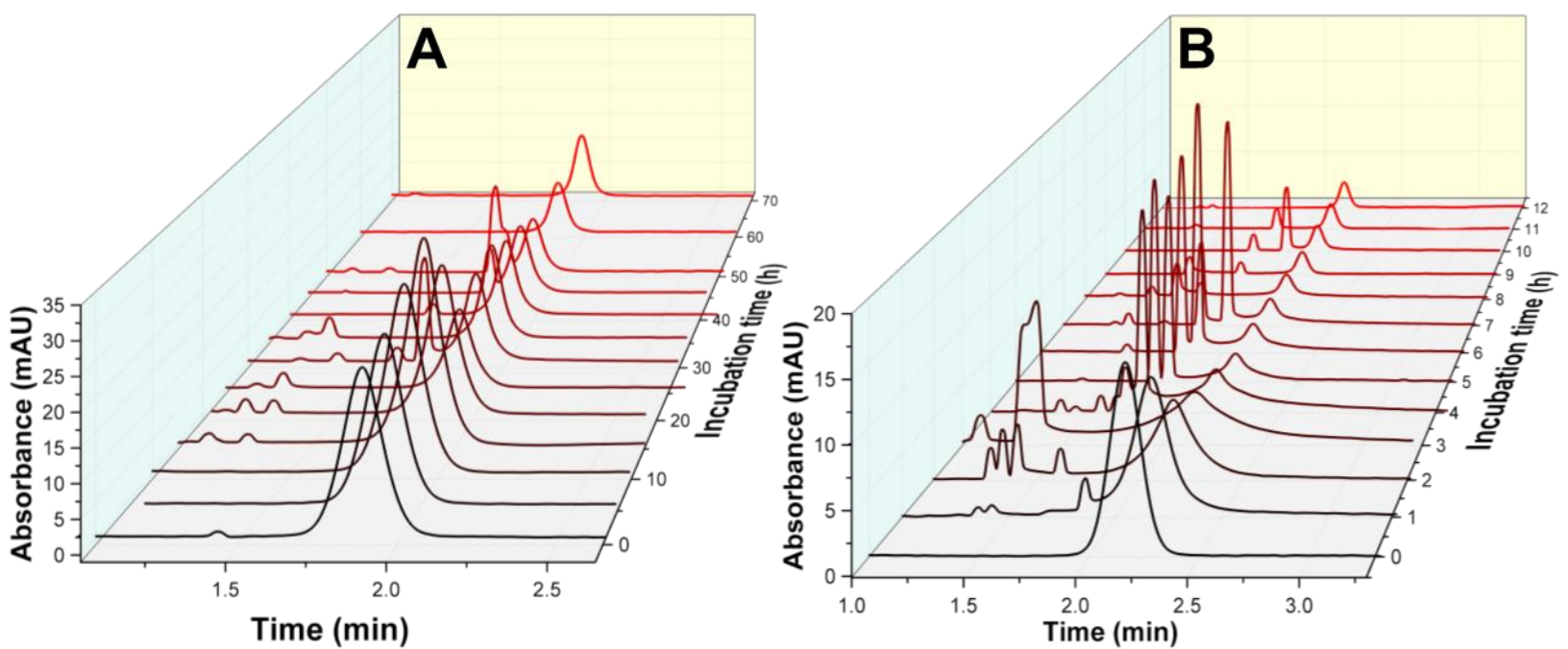

227 Figure 1. Three-dimensional overview of the obtained taylorgrams during the aggregation 228 process of $\mathrm{A} \beta(1-40)$ (A) and $\mathrm{A} \beta(1-42)$ (B) at different incubation times. Experimental 229 conditions: Sample: $100 \mu \mathrm{M} ; 20 \mathrm{mM}$ phosphate buffer, $\mathrm{pH}$ 7.4. Incubation: quiescent conditions 230 at $37{ }^{\circ} \mathrm{C}$. Fused silica capillaries: $50 \mu \mathrm{m}$ i.d. $\times 40 \mathrm{~cm} \times 31.5 \mathrm{~cm}$. Mobile phase: $20 \mathrm{mM}$ 231 phosphate buffer, $\mathrm{pH}$ 7.4. Mobilization pressure: 100 mbar. Injection: 44 mbar for $3 \mathrm{~s}, \mathrm{~V}_{i} \approx 7 \mathrm{~nL}$ $232\left(\mathrm{~V}_{i} / \mathrm{V}_{d} \approx 1 \%\right)$. Analyses were performed at $37^{\circ} \mathrm{C}$. UV detection at $191 \mathrm{~nm}$.

233 In general, the obtained elution profiles were not Gaussian meaning that the sample was 234 polydisperse in size. All taylorgrams were fitted on the basis of the right-side elution profile (i.e. 
$235 t>t_{0}$, with $t_{0}$ the peak time) to get rid of the spikes that are present on the left side. The 236 deconvolution of the right-side of the taylorgram provides valuable information on the 237 aggregation process. Indeed, a complex mixture of components was obtained, composed of 238 varying proportions of $\mathrm{A} \beta$ monomer, intermediate oligomers $\left(R_{h}\right.$ lower than $\left.50 \mathrm{~nm}\right)$, protofibrils 239 ( $R_{h}$ between 50 and $150 \mathrm{~nm}$ ), small molecules (salts, counter ions...) and fibrils/insoluble 240 aggregates (typical dimensions having an average diameter of approximately $7-10 \mathrm{~nm}$ and 241 lengths up to several micrometers were reported for fibrils ${ }^{53-55}$, they are detected as spikes on the 242 taylorgrams). Except for the fibrils and other insoluble aggregates, all components in the mixture 243 could be sized and quantified by TDA. For that, all the elution profiles were deconvoluted using 244 two different approaches to extract the size and proportion of the different populations. A first 245 fitting approach consisted in using a finite number of Gaussian curves $(n=1-4)$. The second 246 fitting approach used the Constrained Regularized Linear Inversion (CRLI) algorithm, which 247 does not require any hypothesis on the number of populations and allows obtaining a continuous 248 distribution of the diffusion coefficient or of the hydrodynamic radius ${ }^{56}$.

249 Figure SI.6 in the supporting information shows two typical examples of deconvolution of a 250 TDA profile for $\mathrm{A} \beta(1-40)$ (Figure SI.6A) and $\mathrm{A} \beta(1-42)$ (Figure SI.6B), at selected incubation 251 times $t_{a g}=25.52 \mathrm{~h}$ and $t_{a g}=1.98 \mathrm{~h}$, respectively. In these examples, four Gaussian functions were 252 used to fit the elution profile, with low residues for the curve fitting on the right side of the 253 profile (see upper part of each Figure). When a lower number of Gaussian functions $(n \leq 3)$ was 254 used, the residues were much higher (see Figure SI.7). It is worth noting that a constraint was 255 added to the fitting procedure on the value of the peak variance of the monomer population, 256 allowing it to vary within $5 \%$ with the respect to that at $t_{a g}=0 \mathrm{~h}$ (initial size of the monomers). 257 Figures SI.8 and SI.9 show the Gaussian peaks extracted from the 4-Gaussian fit for the four 
258 populations and for both peptides, together with their respective area as a function of incubation 259 time.

\section{Monitoring $\mathbf{A} \boldsymbol{\beta}(\mathbf{1 - 4 0 )}$ and $\mathbf{A} \boldsymbol{\beta}(\mathbf{1 - 4 2 )}$ aggregation by TDA.}

261 Figure 2 shows the monitoring of $\mathrm{A} \beta(1-40)$ (Figure $2 \mathrm{~A}$ ) or $\mathrm{A} \beta(1-42)$ (Figure 2B) aggregation

262 using the aforementioned data processing. The lower panels of Figure 2 represent the evolution

263 of the peak area of each population (proportional to its mass abundance), while the middle and

264 upper panels represent the evolution in size $\left(R_{h}\right)$ of these populations. The populations were

265 classified by size into four groups. In the first group, some small molecules $\left(R_{h}=0.3-0.4 \mathrm{~nm}\right)$

266 were detected (blue down triangles). Their size as well as their abundance (peak area) were

267 constant throughout the aggregation, and their presence seems therefore not related to the

268 aggregation process. The second population (red squares) had a size of $1.99 \pm 0.09 \mathrm{~nm}$ for $\mathrm{A} \beta(1$ -

$26940)$ and $1.94 \pm 0.12 \mathrm{~nm}$ for $\mathrm{A} \beta(1-42)$, and was attributed to the monomeric and small oligomeric

270 forms of the peptides (up to dodecamers, see next section). The third population was attributed to

271 higher molar mass oligomers with $R_{h}$ between 4 and $50 \mathrm{~nm}$. The average size of this population

272 over the whole aggregation process was $24.9 \pm 10.3 \mathrm{~nm}$ for $\mathrm{A} \beta(1-40)$ and $10.8 \pm 6.1 \mathrm{~nm}$ for

$273 \mathrm{~A} \beta(1-42)$. The fourth population with $R_{h}>50 \mathrm{~nm}$ was attributed to soluble protofibrillar

274 structures with an average size of $119 \pm 49 \mathrm{~nm}$ for $\mathrm{A} \beta(1-40)$ and $110 \pm 39 \mathrm{~nm}$ for $\mathrm{A} \beta(1-42)$. 


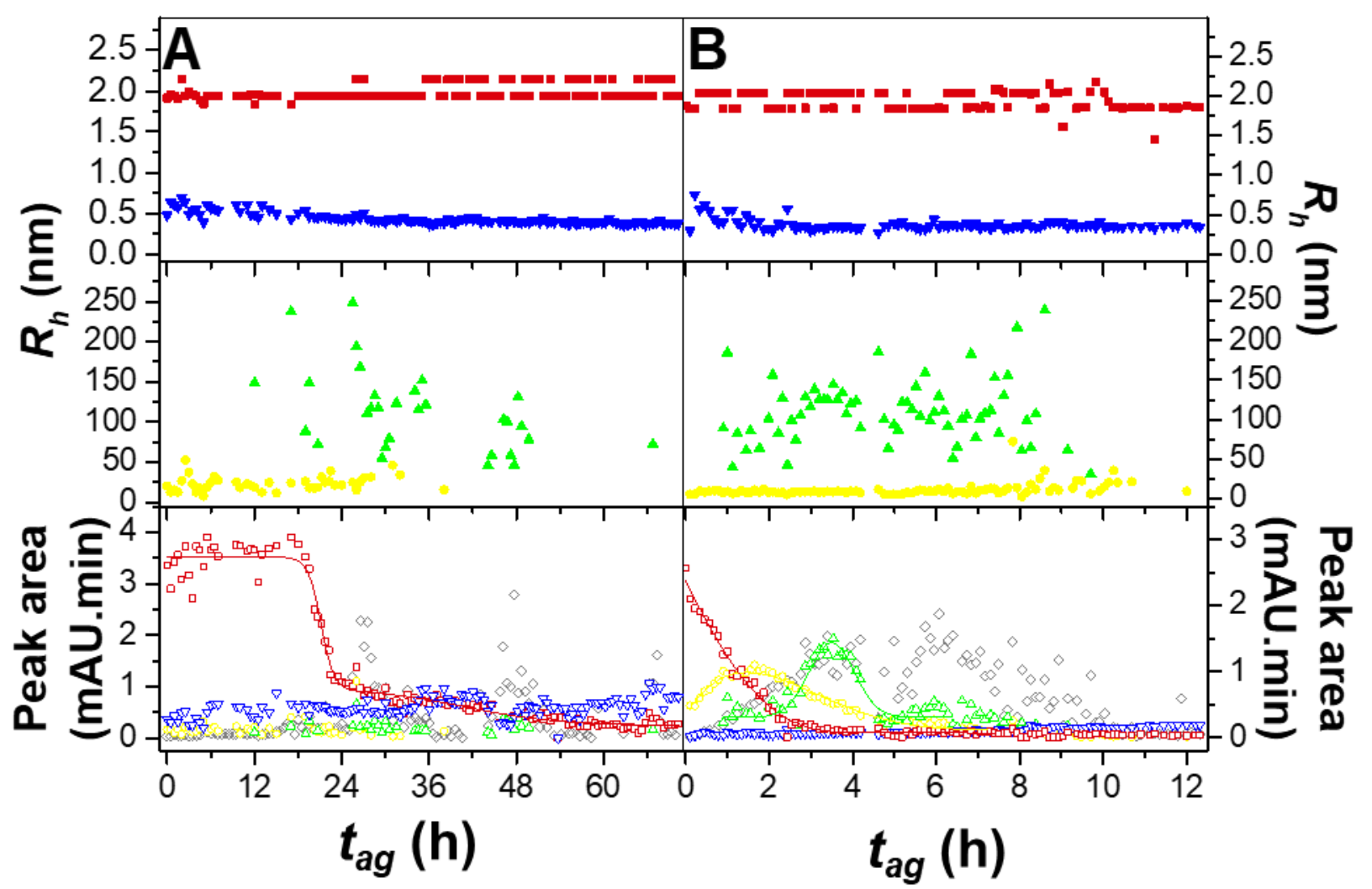

275

276

277

278

279

280

281

282

283

284

285

286

287

288

289

Figure 2. Hydrodynamic radius and peak area evolution of the different populations observed during the aggregation process of $A \beta(1-40)(A)$ and $A \beta(1-42)(B)$ using a 4 Gaussians fitting of the taylorgrams. Closed symbols are for the hydrodynamic radius: small molecules (B), monomer and low molar mass oligomers (!), higher molar mass oligomers (), and soluble protofibrils (7). Open symbols correspond to the peak area of each species: small molecules (X), monomer and low molar mass oligomers $(\forall)$, higher molar mass oligomers (-), soluble protofibrils (8) and fibrils (M) (spikes). The straight lines are guides for the eyes. Experimental conditions as in Figure 1.

For the $A \beta(1-40)$, only the monomeric and low molar mass oligomers populations were significantly present in the sample (see open red squares in Figure 2A), as compared to the high molar mass oligomers and protofibrils populations (open yellow circles and open green triangles, respectively), which were much less abundant. The red traces in Figure $2 \mathrm{~A}$ showed that A $\beta(1-40)$ was essentially in its monomeric form and remained so up to $t_{a g} \sim 18 \mathrm{~h}$. Afterwards, the peak area of the monomeric population rapidly dropped to reach a lower plateau at $t_{a g} \sim 24 \mathrm{~h}$. It is 
290 important to note that despite the disappearance of the monomeric form, no other soluble species

291 yielded a significant signal in TDA. Indeed, the aggregation of $A \beta(1-40)$ displayed a threshold-

292 type behavior, which indicates that the rate-determining step for aggregation is the formation of

293 multimeric seeds. In other words, our results seem to indicate that $A \beta(1-40)$ goes through a

294 secondary nucleation mechanism where monomers add to already present fibrils to elongate

295 them and to produce larger fibrils, without going through intermediate species in accordance

296 with what is discussed in the literature ${ }^{57,58}$. To confirm this hypothesis, a slight manual shaking

297 of the vial was done at $25 \mathrm{~h}, 48 \mathrm{~h}$ and $70 \mathrm{~h}$, in order to resuspend any precipitate/fibrils that may

298 have sedimented. After each remixing, a significant increase of the peak area of the "spikes"

299 (open grey diamonds in the lower part of Figure 2A) was transiently observed, proving the

300 presence of insoluble species in the sample that suspend upon shaking and then tend to decant.

301 The aggregation process for $A \beta(1-42)$ displayed a different pathway as compared to that of $302 \mathrm{~A} \beta(1-40)$. For $A \beta(1-42)$ the proportion of monomeric and low molar mass oligomeric 303 populations decreased rapidly, while the higher molar mass oligomeric species increased to reach 304 a maximum at $t_{a g}=1.6 \mathrm{~h}$, after the disappearance of the monomeric species. Subsequently, the 305 protofibrils proportion increased to reach a maximum at $t_{a g}=3.5 \mathrm{~h}$, and finally the spikes (non306 diffusing species in suspension) increased to reach a maximum at $t_{a g}=5.6 \mathrm{~h}$. From these 307 observations, it is evident that TDA experiments gives a clear picture of the early stages of the 308 aggregation process of the $\mathrm{A} \beta(1-42)$ that goes through a primary nucleation leading to 309 intermediate species and successively an elongation step producing protofibrils and then fibrils.

310 The results for $A \beta(1-40)$ and $A \beta(1-42)$ obtained by fitting the taylorgram to $n$ Gaussians were

311 compared to the evolution of the $R_{h}$ distributions obtained by $\mathrm{CRLI}^{56}$, as shown in the supporting

312 information (Figures SI.10, SI.11, SI.12 and SI.13). Continuous distributions of the 
313 hydrodynamic radius for each run (Figures SI.10 and SI.11) were obtained by CRLI algorithm,

314 allowing for a full and quantitative characterization of the aggregation process. The CRLI

315 analysis confirmed the two different pathways that were inferred for the aggregation of $A \beta(1-40)$

316 and $\mathrm{A} \beta(1-42)$ on the basis of the $n$-Gaussians fits.

317 Another way to qualitatively and visually assess the entire aggregation process and the speciation

318 of the amyloid peptides during the aggregation process is shown in Figure 3, which displays a

319 stacked bar representation of the peak area of each population. The grey region represents the

320 insoluble species that can enter the capillary and appear as spikes as well as those that precipitate

321 and no longer enter in the capillary at the injection step, lowering the total observed peak area

322 over incubation time. From this Figure, one can clearly distinguish the two different aggregation

323 pathways ${ }^{32,59}$.
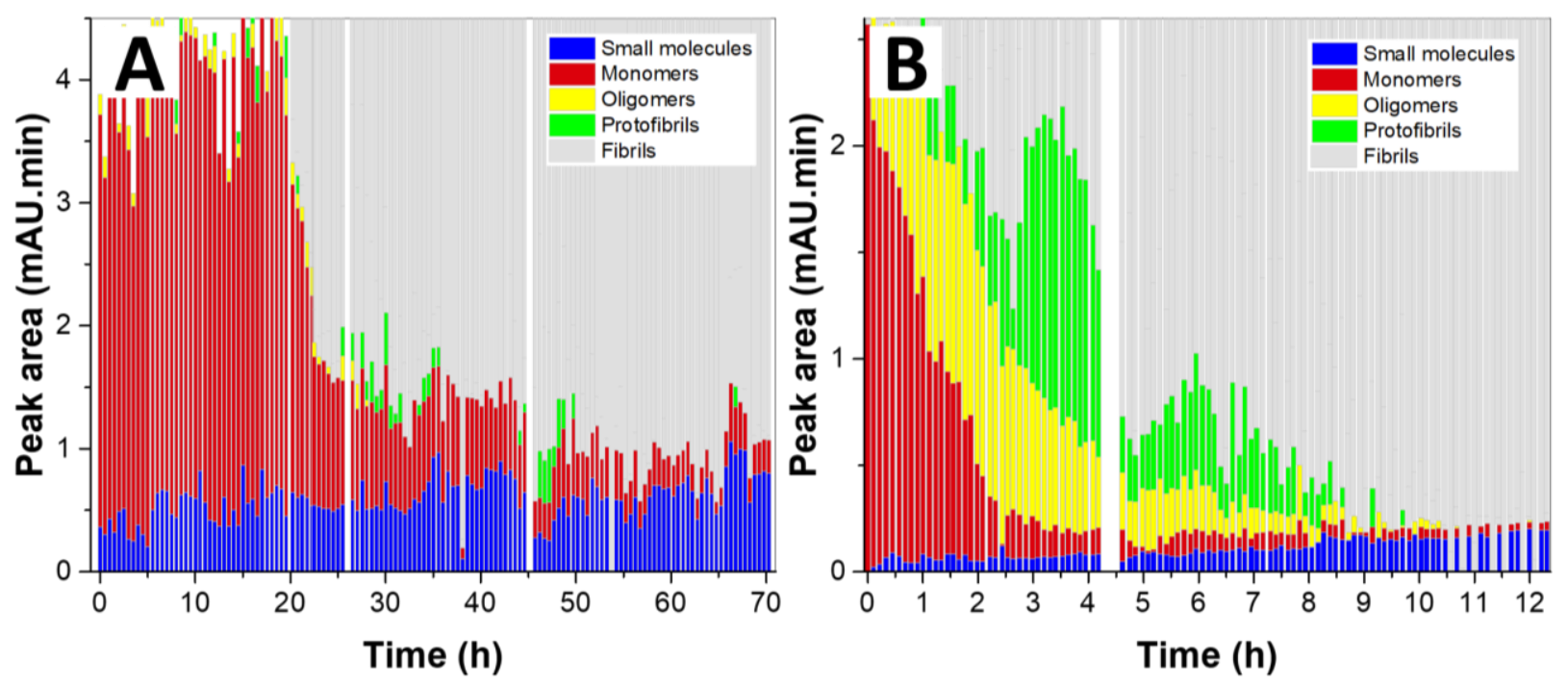

325 Figure 3. Stacked bar graphs showing the speciation of $A \beta(1-40)(A)$ and $A \beta(1-42)$ (B) at each 326 analyzed incubation time obtained by TDA. Experimental conditions as in Figure 1. Four 327 populations are distinguished: "small molecules" for $R_{h} \sim 0.4 \mathrm{~nm}$; "monomers" for the monomer 328 and the low molar mass oligomers with $R_{h} \sim 1.9 \mathrm{~nm}$, "oligomers" for high molar mass oligomers 329 with $R_{h}$ between 4 and $50 \mathrm{~nm}$; and "protofibrils" for large diffusing soluble species with $R_{h}$ 
330 between 50 and $150 \mathrm{~nm}$. Each population is represented by the corresponding peak area obtained 331 by 4 Gaussian curve fitting. The population in grey represents the fibrils but were not quantified 332 by TDA and are just represented by difference.

333 To confirm these observations, the ThT assay was realized in the same conditions as the TDA 334 analysis. The ThT assay is best known to detect the amyloid fibrillary structures, which are

335 formed at the expense of the soluble ones causing a decrease in their proportion. As seen in

336 Figure SI.14, the ThT assay curve superimpose on the concentration evolution of the insoluble

337 species determined by TDA, demonstrating that TDA faithfully captures the lag phase and the

338 time to reach the plateau of the aggregation process. Additionally, TDA allowed for a 339 quantitative estimation of the intermediate steps of the aggregation, especially in the case of $340 \mathrm{~A} \beta(1-42)$, a feature difficult to obtain ${ }^{57}$ with other techniques such as $\mathrm{SEC}^{25}$.

341 Discussion on the size of the $\mathbf{A} \boldsymbol{\beta}$ species during the aggregation process.

342 Regarding the size of the aggregated forms, it was suggested from combined results obtained by 343 NMR, FTIR and AFM, that $\mathrm{A} \beta(1-42)$ rapidly forms low molar mass oligomers upon 344 solubilization ${ }^{60}$. The predominant forms ranged from dimer to dodecamer ${ }^{59,61}$ including some 345 assemblies (from tetramer to octamer) called "paranuclei" 32 , which were in equilibrium with the 346 lower molar mass oligomers. Several methods were used in the literature to identify the nature of 347 these oligomers. Ion mobility MS allows to get structural information relative to the oligomeric 348 molar mass distribution ${ }^{29}$, however, the separation is obtained in gas phase which can perturb the 349 oligomeric distribution. Further, ion suppression effect may also occur for quantitative analysis 350 in complex mixtures ${ }^{62}$. Real-time aggregation monitoring methods such as dynamic light 351 scattering (DLS) are very difficult to apply to detect the presence of small oligomers in 352 polydisperse samples, especially in the presence of large aggregates. TDA has the advantage of 
353 being less sensitive to the presence of very large aggregates ${ }^{36,63}$ allowing the detection of the 354 early stage species, without bias in the mass-weighted size distribution. For the sake of 355 comparison, DLS experiments were realized on the $A \beta(1-42)$ sample in the same conditions as in 356 TDA. From the obtained size distributions, $P_{M}\left(R_{h}\right)$, we integrated over four intervals, so as to 357 obtain the mass-weighted relative contribution of four classes of aggregates, with $R_{h}<5 \mathrm{~nm}, 5$ $358 \mathrm{~nm}<R_{h}<50 \mathrm{~nm}, 50 \mathrm{~nm}<R_{h}<500 \mathrm{~nm}$, and $R_{h}>500 \mathrm{~nm}$, respectively (see Methods for 359 details). Figure SI.15 shows the time evolution of the (mass-weighted) fractions of the four 360 classes of aggregates thus obtained. The data shown in the figure correspond to the average of 361 results obtained by processing separately data collected at scattering angles $\theta=90^{\circ}$ and $\theta=45^{\circ}$; $362 x$ and $y$ error bars indicate the half-difference between the corresponding pairs of data at $90^{\circ}$ and $36345^{\circ}$. In contrast to TDA results, dimers and small oligomers, corresponding to $R_{h}<5 \mathrm{~nm}$, are not 364 detected by DLS, because their scattered intensity is much weaker than that of larger species. On 365 the other hand, DLS detects large aggregates, including objects up to several hundred nm, which 366 are beyond the range accessible to TDA. Aggregates with $R_{h}>500 \mathrm{~nm}$ are detected as early as at $367 t_{a g}=500 \mathrm{~s}$. Their relative contribution increases significantly for $t_{a g}>1200 \mathrm{~s}(0.33 \mathrm{~h})$, at the 368 expenses of both intermediate $\left(50 \mathrm{~nm}<R_{h}<500 \mathrm{~nm}\right)$ and smaller $\left(5 \mathrm{~nm}<R_{h}<50 \mathrm{~nm}\right)$ 369 aggregates. These results show that DLS is a powerful technique able to follow in real time the 370 evolution of the larger size species. However, in contrast to TDA, the sensitivity of DLS toward 371 the smaller size species is quite limited. Thus, TDA and DLS are complementary methods.

372 In order to propose possible oligomeric structures that fit with the size of each population found 373 by TDA, molecular simulation was performed based on $\mathrm{A} \beta(1-42)$ monomers (folded and 374 unfolded) ${ }^{64}$ and oligomers ${ }^{65,66}$ structures found in the literature (low and high molar mass, from 2 375 to 360 monomer units). Different 3D molecular structures were constructed using the UCSF 
376 Chimera $X$ software ${ }^{67}$ that were next loaded into HYDROPRO+ ${ }^{48}$ software to calculate the 377 hydrodynamic properties. The 3D structures were adjusted so that the calculated translational 378 diffusion coefficients equals the experimental values obtained by TDA for each population. 379 Figures 4 and 6 display possible conformations for small and large oligomers thus obtained.

380 Different $A \beta(1-42)$ monomer structures were considered, based on the structures published by 381 Tomaselli et al. ${ }^{64}$ (PDB code 1Z0Q), Lührs et al. ${ }^{68}$ (PDB code 2BEG) and Colvin et al. ${ }^{66}$ (PDB 382 code 5KK3). Results show hydrodynamic radii around $1.5 \mathrm{~nm}$ for the different conformations 383 (see Figure 4, monomer structures). The average hydrodynamic radii of the "monomer and small 384 oligomers" population obtained by TDA on all runs over the whole A $\beta(1-42)$ aggregation study $385\left(t_{a g}=12.5 \mathrm{~h}, n=110\right.$ TDA runs $)$ was of $1.94 \mathrm{~nm}(\mathrm{RSD}=5.9 \%)$ and the initial size at $t_{a g}=0 \mathrm{~h}$ 386 was $1.84 \mathrm{~nm}$. To correlate the observed experimental size with oligomeric structures, different 387 proposed oligomeric structures from the literature, ranging from dimer to dodecamer with 388 different conformations were used and computed to get the hydrodynamic radii (Figure 4) (PDB 389 codes $5 \mathrm{AEF}^{69}, 2 \mathrm{NAO}^{70}, 5 \mathrm{HOX}^{71}, 6 \mathrm{RHY}^{72}$ and $2 \mathrm{MXU}^{73}$ ). The latter structures were determined 390 by electron cryo-microscopy ${ }^{69}$, solid state $\mathrm{NMR}^{70,73}$, X-ray crystallography ${ }^{71}$ and $\mathrm{NMR}^{72}$. The 391 combination of our results and those from the literature, suggest that the "monomer and small 392 oligomers" population at $t_{a g}=0 \mathrm{~h}$ was mainly composed of monomers and dimers ${ }^{74}$. The weight393 average $R_{h}$ obtained by TDA is sensitive to the mass proportion of all the soluble species present 394 in the mixture. The CRLI analysis brings additional information about the polydispersity of each 395 population mode (see Figure 5). However, due to the low difference in $R_{h}$ of the various small 396 species (monomers / dimers / trimers) neither the CRLI nor the Gaussian fitting approaches were 397 able to resolve these small species. CRLI shows that the size distribution of the "monomer and 398 small oligomers" population at $t_{a g}=0 \mathrm{~h}$ ranges between 1 and $3 \mathrm{~nm}$ and is centered around 1.9 
$399 \mathrm{~nm}$. The polydispersity in size of this mode increases with increasing incubation times. This 400 population becomes negligible after $t_{a g} \sim 2-4 \mathrm{~h}$. Several reports ${ }^{75-77}$ suggested the presence of a 401 critical nucleus size, which is the minimum size that enables the extension of amyloid fibrils. To 402 our knowledge, no consensus was reached on the exact size of the nuclei, while other reports 403 stated that the nucleation was heterogeneous ${ }^{78,79}$. However, aggregation numbers between 2 and

40414 were reported ${ }^{75-77,80,81}$, which according to this work would correspond to a size distribution 405 between 1.8 and $\sim 3 \mathrm{~nm}$, thus the first oligomer size population found by TDA. 


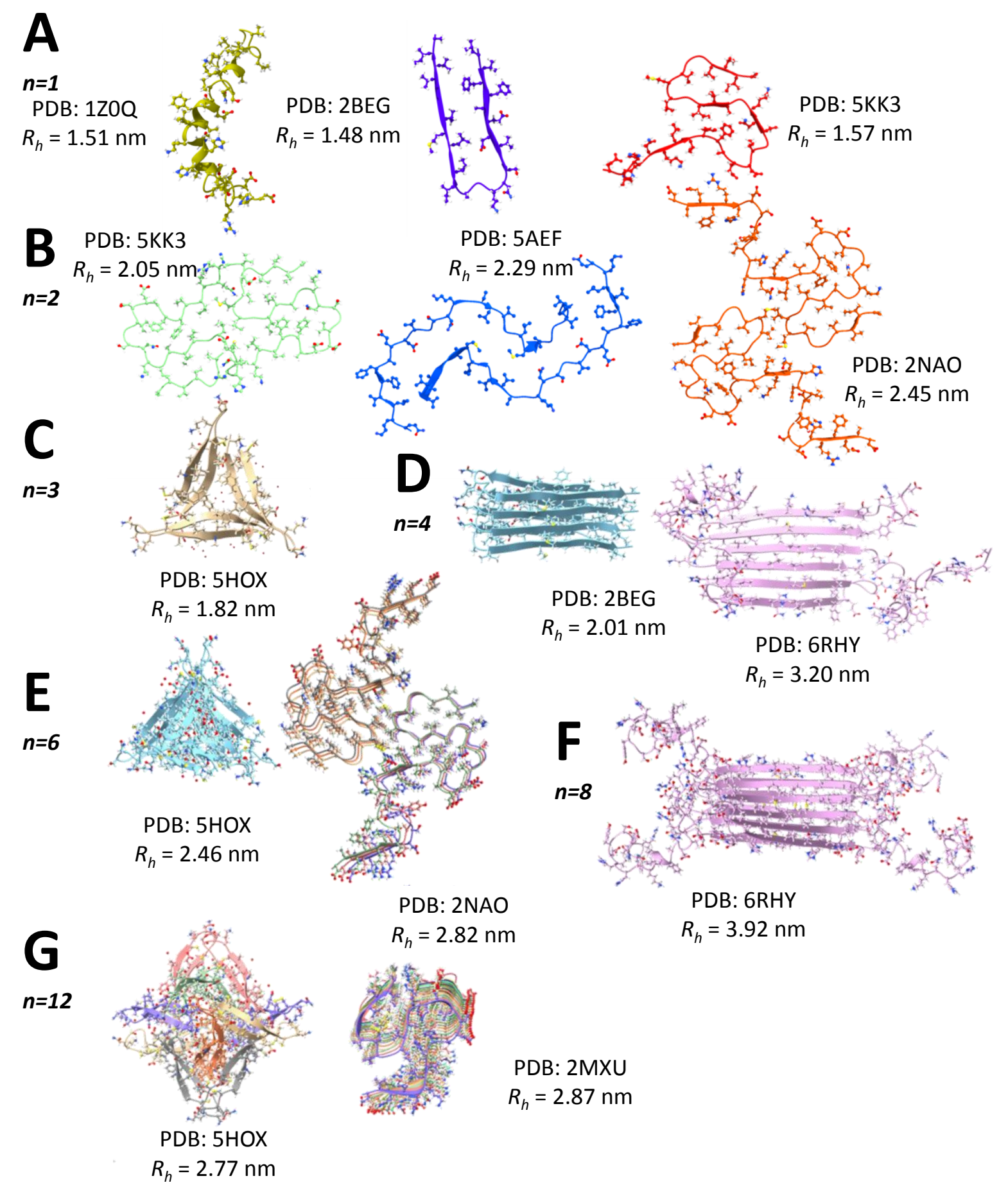

407 Figure 4. Schematic representation of the monomeric $\mathrm{A} \beta(1-42)$ (A) and small-oligomer 408 conformations from dimers to dodecamers (B to $G$ represent dimers, trimers, tetramers, 409 hexamers, octamers and dodecamers respectively). The 3D structures were realized using the 410 UCSF Chimera $X$ software ${ }^{67}$ and were adapted from the structure found in the literature (PDB 411 codes $1 \mathrm{Z} 0 \mathrm{Q}^{64}, 2 \mathrm{BEG}^{68}$ and $5 \mathrm{KK} 3^{66}$ ). The arrangement of the monomers in the oligomeric forms 412 were adapted from the literature (PDB codes $5 \mathrm{AEF}^{69}, 2 \mathrm{NAO}^{70}, 5 \mathrm{HOX}^{71}, 6 \mathrm{RHY}{ }^{72}$ and $2 \mathrm{MXU}^{73}$ ). 
413 The $R_{h}$ were calculated by introducing the generated PDB files for each structure into the 414 HYDROPRO software ${ }^{48}$. It is worth noting that the $R_{h}$ calculation takes into account all possible 415 orientations of the molecular structure relative to the flow direction.

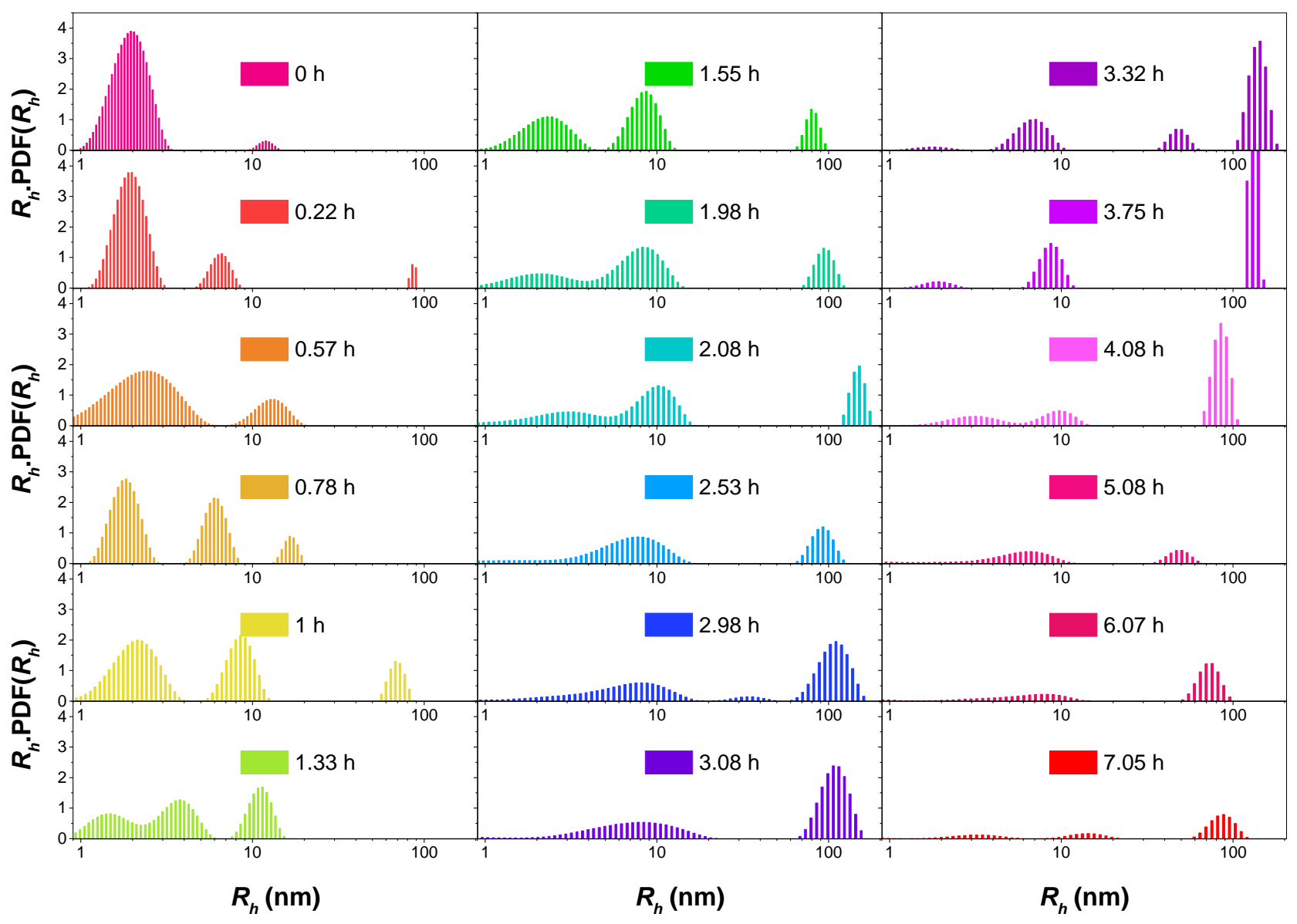

418 Figure 5. Size distributions of $\mathrm{A} \beta(1-42)$ obtained by CRLI analysis of the experimental 419 taylorgrams as a function of incubation time $t_{a g}=0$ to $7 \mathrm{~h}$. Experimental taylorgrams and 420 conditions as in Figure 1.

421 In order to identify the structure beneath the distribution of the "high molar mass oligomer" 422 population, the same approach was applied by constructing 3D models and calculating their 423 hydrodynamic radii. In fact, several $\mathrm{NMR}^{66,70}$ or cryo-EM ${ }^{82}$ studies have shown that the fibril 424 core of $A \beta(1-42)$ consisted of a dimer, each monomer containing four $\beta$-strands in an $S$-shaped 
425 amyloid fold arrangement (Figure SI.16). On these grounds, protofibrillar and fibrillar structures 426 were constructed, using the $\mathrm{PDB}$ file code $5 \mathrm{KK} 3^{66}$, to get structures having a parallel 427 superposition of dimers and ranging from one dimer unit (disc shaped with a width of $\sim 6.4 \mathrm{~nm}$ 428 and a length of $\sim 0.9 \mathrm{~nm}$ ) up to 720 dimer units (cylinder shaped with a width of $\sim 6.4 \mathrm{~nm}$ and a 429 length of $\sim 345 \mathrm{~nm}$ ). The calculated size for the constructed oligomers is given in Table SI.1 and 430 in Figure 6. From the TDA analysis, the minimum size calculated for the high molar mass 431 oligomers distribution based on the results obtained on the simulated structures in Figure 6 was $4325.1 \mathrm{~nm}$, and corresponded to an oligomer having 33 dimer units ( 300 kDa) and dimensions of $43317 \mathrm{~nm}$ in length and $3.2 \mathrm{~nm}$ in radius. The maximum size was $36 \mathrm{~nm}$ corresponding to 434 approximately 700 dimer units $(\sim 6300 \mathrm{kDa})$ and dimensions of $\sim 335 \mathrm{~nm}$ in length and $3.2 \mathrm{~nm}$ in 435 radius. Further, over the whole aggregation process (110 TDA runs), the average size was 10.7 $436 \mathrm{~nm}$ corresponding to a cylinder-shaped oligomer having $\sim 115$ dimer units $(\sim 1035 \mathrm{kDa})$ with a 57 $437 \mathrm{~nm}$ length and a $3.2 \mathrm{~nm}$ radius. The CRLI analysis on the TDA runs of $\mathrm{A} \beta(1-42)$ aggregation 438 (Figure 5) showed that the "high molar mass oligomer" population, centered around $10 \mathrm{~nm}$, was 439 present at $t_{a g}=0 \mathrm{~h}$ at a very low concentration as compared to that of the "monomer and small 440 oligomers" population. These observations are in agreement with data obtained on $A \beta(1-42)$ by 441 FCS where stable micelle-like oligomers with a size of $R_{h} \approx 7-11 \mathrm{~nm}$ and having $28-88$ mers 442 were observed ${ }^{83}$. The abundance of this population then increased with incubation time to reach 443 a maximum at $2 \mathrm{~h}$, and finally became negligible after about $7 \mathrm{~h}$.

444 Further, both the deconvolution using $n$ Gaussian functions and the CRLI analysis showed that a 445 larger sized population, appeared after $1 \mathrm{~h}$ and reached a maximum at $3 \mathrm{~h}$, and then became 446 negligible after $7 \mathrm{~h}$. We attributed this population to protofibrils since they are still soluble. 447 Indeed, TDA has shown that this population had a size $\left(R_{h}\right)$ ranging between 50 and $240 \mathrm{~nm}$ with 
448 an average value of $113 \mathrm{~nm}$ over the whole aggregation process ( $n=110$ TDA runs). If the same

449 calculations were naively applied as done for the "high molar mass oligomers", structures having

450 a length between $500 \mathrm{~nm}$ and up to $8.5 \mu \mathrm{m}$ would be obtained, with an average length around 2.2

$451 \mu \mathrm{m}$. The number of dimer units in these estimated elongated structures would range between

4521200 and 18000 (average of 4650) (with a molar mass per unit length of about $19 \mathrm{kDa} / \mathrm{nm}$ ).

453 Nevertheless, one should keep in mind that TDA cannot give reliable information about the 454 shape of these assemblies, only the $R_{h}$ distribution is obtained. Other techniques such as AFM 455 would be more suited for looking at the molecular structure ${ }^{84,85}$. Despite this limitation, which is 456 common to all methods based on the determination of the diffusion coefficient (or $R_{h}$ ), the 457 present work demonstrates that TDA in combination with molecular simulations can rapidly and 458 advantageously propose a limited number of possible molecular conformations that are 459 consistent with the experimental data.

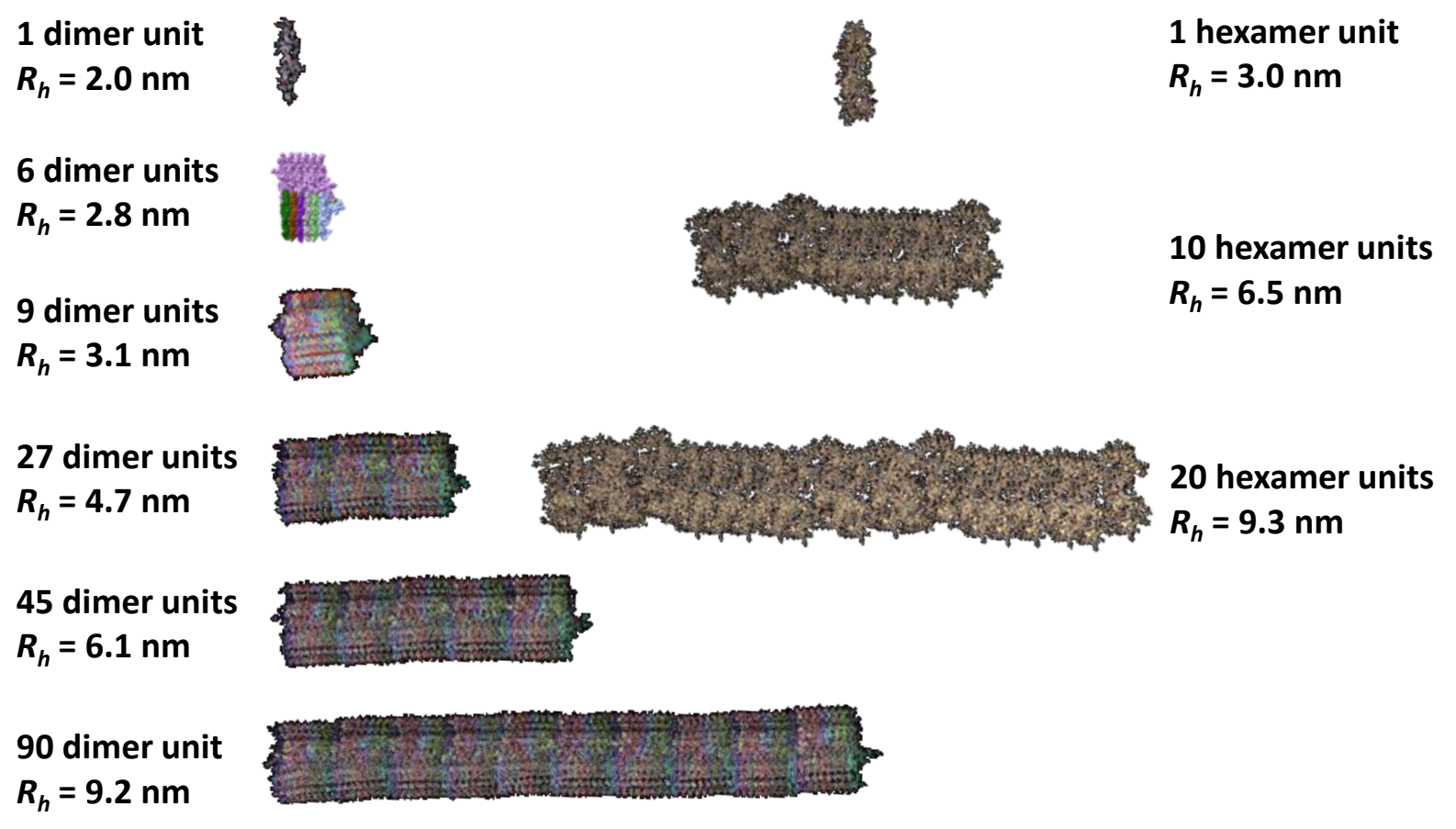

Figure 6. Schematic side view representation of possible conformations for the "high molar 462 mass oligomeric $A \beta(1-42)$ " population. The arrangement of the monomers in the oligomeric 
463 form was based on the structures described by Colvin et al. ${ }^{66}$ and in Tran et al. ${ }^{65}$. The 3D 464 structures were realized using UCSF Chimera X software ${ }^{67}$ and were adapted from the structure 465 published in ${ }^{64}$ (PDB code 1Z0Q) for the hexameric structures and in ${ }^{66}$ (PDB code 5KK3) for the 466 dimeric structures. The $R_{h}$ were calculated by introducing the generated PDB files for each 467 structure into HYDROPRO software ${ }^{48}$. The dimer, the hexamer, the dodecamer and the 468 octadecamer, which size is lower than $4 \mathrm{~nm}$, are represented for the sake of comparison.

470 Finally, reports from the literature found that toxic $\mathrm{A} \beta$ oligomers had a molar mass higher than

$47150 \mathrm{kDa}^{86,87}$ which corresponded to oligomers having more than $\sim 11$ monomer units. One of the 472 most toxic reported oligomers was identified to be $A \beta^{* 56}(56 \mathrm{kDa})^{88}$ corresponding to a 473 dodecamer. Based on the calculations described in this work, a dodecamer would have $R_{h}$ around $4742.8 \mathrm{~nm}$, if it is formed by the superposition of dimers or of monomers (as depicted in ${ }^{73}$ ). The size 475 of the dodecamer would increase to $3.4 \mathrm{~nm}$ if constituted by the superposition of two hexamers. 476 According to another report ${ }^{10}$, the toxicity of $A \beta(1-42)$ oligomers decreases with increasing size, 477 and toxic oligomers are likely in the range of 8-24-mers, having an $R_{h}$ between 3 and $4.2 \mathrm{~nm}$, as 478 calculated in this work. From the CRLI analysis in Figure 5, this fraction of potentially toxic 479 oligomers appears after $30 \mathrm{~min}$, and then tends to decrease in proportion with the aggregation 480 time as the oligomer size is increasing.

\section{Conclusion}

482 This work demonstrates that TDA can be used for the straightforward monitoring of the 483 aggregation of $\mathrm{A} \beta$ amyloid peptides. Further, by using an appropriate data treatment of the 484 taylorgrams, one can assess the aggregation pathway by obtaining quantitative data on the 485 proportion and the size of the different aggregated forms. To our knowledge, there is no other 486 real-time aggregation monitoring method reported in the literature allowing to obtain such 
487 information in one single analysis. It is worth noting that low volume was used for each 488 aggregation study (total volume of $1 \mu \mathrm{L}$ of a $100 \mu \mathrm{M}$ peptide solution) with an unprecedented 489 large number of data points during the aggregation process (about 10 points/h) leading to large 490 amount of valuable data.

491 The results obtained in this work tend to confirm the aggregation pathway of $A \beta(1-40)$ which 492 goes from the monomeric state directly to a fibrillary structure, in contrast to A $\beta(1-42)$ which 493 goes through different intermediate states (oligomers and protofibrils) before reaching the fibrils, 494 in agreement with previous work ${ }^{58,60}$. In addition TDA data gave new insights for the 495 identification of the formed oligomers in the early stages of the aggregation process, including 496 the characterization of the size and abundance evolution of disease-relevant amyloids peptides in 497 solution. The strength of the data processing described in this work lies in its ability to 498 distinguish the small, potentially toxic, oligomers in a polydisperse mixture of larger oligomers, 499 protofibrils and fibrils. In the future, it will be interesting to investigate experimental conditions 500 mimicking the in vivo environment, such as lower concentrations of the peptides (in the $100 \mathrm{nM}$ 501 range), mixtures of different amyloid peptides and the physico-chemical properties (ionic 502 strength, $\mathrm{pH}$ and composition) mimicking the cerebrospinal fluid.

\section{ACKNOWLEDGEMENTS}

505 LC gratefully acknowledges support from the Institut Universitaire de France (IUF)

\section{Supporting information}

508 Experimental procedure for the synthesis; Theoretical aspects and data processing of TDA; raw 509 TDA data; ThT assay results; DLS results; modelization data. 


\section{References}

511 (1) Association, A. s., 2019 Alzheimer's disease facts and figures; Alzheimer's \& Dementia 512155252602019.

513 (2) Folch, J.; Ettcheto, M.; Petrov, D.; Abad, S.; Pedrós, I.; Marin, M.; Olloquequi, J.; Camins,

514 A. Review of the advances in treatment for Alzheimer disease: strategies for combating $\beta$ -

515 amyloid protein. Neurología (English Edition) 2018, 33, 47-58.

516 (3) Hardy, J. A.; Higgins, G. A. Alzheimer's disease: the amyloid cascade hypothesis. Science

517 1992, 256, 184-185.

518 (4) Liu, P.-P.; Xie, Y.; Meng, X.-Y.; Kang, J.-S. History and progress of hypotheses and clinical trials for Alzheimer's disease. Signal Transduction and Targeted Therapy 2019, 4, 29. (5) Forloni, G.; Balducci, C. Alzheimer's Disease, Oligomers, and Inflammation. J. Alzheimers Dis. 2018, 62, 1261-1276.

(6) Heppner, F. L.; Ransohoff, R. M.; Becher, B. Immune attack: the role of inflammation in Alzheimer disease. Nature Reviews Neuroscience 2015, 16, 358-372.

(7) Terry, R. D. The Pathogenesis of Alzheimer Disease: An Alternative to the Amyloid Hypothesis. J. Neuropathol. Exp. Neurol. 1996, 55, 1023-1025.

(8) Hayden, E. Y.; Teplow, D. B. Amyloid $\beta$-protein oligomers and Alzheimer's disease. Alzheimers Res. Ther. 2013, 5, 60.

(9) Selkoe, D. J.; Hardy, J. The amyloid hypothesis of Alzheimer's disease at 25 years. EMBO Mol. Med. 2016, 8, 595-608.

(10) Sengupta, U.; Nilson, A. N.; Kayed, R. The Role of Amyloid- $\beta$; Oligomers in Toxicity, Propagation, and Immunotherapy. EBioMedicine 2016, 6, 42-49.

(11) Lambert, M. P.; Barlow, A. K.; Chromy, B. A.; Edwards, C.; Freed, R.; Liosatos, M.; Morgan, T. E.; Rozovsky, I.; Trommer, B.; Viola, K. L.; Wals, P.; Zhang, C.; Finch, C. E.; Krafft, G. A.; Klein, W. L. Diffusible, nonfibrillar ligands derived from A $\beta_{1-42}$ are potent central nervous system neurotoxins. Proc. Natl. Acad. Sci. U. S. A. 1998, 95, 6448-6453.

(12) Mastroeni, D.; Nolz, J.; Khdour, O. M.; Sekar, S.; Delvaux, E.; Cuyugan, L.; Liang, W. S.; Hecht, S. M.; Coleman, P. D. Oligomeric amyloid $\beta$ preferentially targets neuronal and not glial mitochondrial-encoded mRNAs. Alzheimer's \& Dementia 2018, 14, 775-786.

(13) Walsh, D. M.; Klyubin, I.; Fadeeva, J. V.; Cullen, W. K.; Anwyl, R.; Wolfe, M. S.; Rowan, M. J.; Selkoe, D. J. Naturally secreted oligomers of amyloid $\beta$ protein potently inhibit hippocampal long-term potentiation in vivo. Nature 2002, 416, 535-539. (14) Salazar, S. V.; Strittmatter, S. M. Cellular prion protein as a receptor for amyloid- $\beta$ oligomers in Alzheimer's disease. Biochem. Biophys. Res. Commun. 2017, 483, 1143-1147. (15) König, A. S.; Rösener, N. S.; Gremer, L.; Tusche, M.; Flender, D.; Reinartz, E.; Hoyer, W.; Neudecker, P.; Willbold, D.; Heise, H. Structural details of amyloid $\beta$ oligomers in complex with human prion protein as revealed by solid-state MAS NMR spectroscopy. J. Biol. Chem. 2021, 100499.

(16) Guerrero-Muñoz, M. J.; Castillo-Carranza, D. L.; Sengupta, U.; White, M. A.; Kayed, R. Design of Metastable $\beta$-Sheet Oligomers from Natively Unstructured Peptide. ACS Chem.

Neurosci. 2013, 4, 1520-1523.

(17) Bemporad, F.; Calloni, G.; Campioni, S.; Plakoutsi, G.; Taddei, N.; Chiti, F. Sequence and structural determinants of amyloid fibril formation. Acc. Chem. Res. 2006, 39, 620-627.

(18) Ghosh, P.; Kumar, A.; Datta, B.; Rangachari, V. In BMC Bioinformatics, 2010, p S24. 
(19) Jeong, J. S.; Ansaloni, A.; Mezzenga, R.; Lashuel, H. A.; Dietler, G. Novel mechanistic insight into the molecular basis of amyloid polymorphism and secondary nucleation during amyloid formation. J. Mol. Biol. 2013, 425, 1765-1781. (20) Petkova, A. T.; Leapman, R. D.; Guo, Z.; Yau, W. M.; Mattson, M. P.; Tycko, R. Selfpropagating, molecular-level polymorphism in Alzheimer's $\beta$-amyloid fibrils. Science 2005, 307, 262-265. (21) Watanabe-Nakayama, T.; Ono, K.; Itami, M.; Takahashi, R.; Teplow, D. B.; Yamada, M. High-speed atomic force microscopy reveals structural dynamics of amyloid $\beta 1-42$ aggregates. Proc. Natl. Acad. Sci. U. S. A. 2016, 113, 5835-5840.

(22) Vassar, P. S.; Culling, C. F. Fluorescent stains, with special reference to amyloid and connective tissues. Arch. Pathol. 1959, 68, 487-498.

(23) Bieschke, J.; Zhang, Q.; Powers, E. T.; Lerner, R. A.; Kelly, J. W. Oxidative Metabolites Accelerate Alzheimer's Amyloidogenesis by a Two-Step Mechanism, Eliminating the Requirement for Nucleation. Biochemistry 2005, 44, 4977-4983.

(24) Yang, T.; Li, S.; Xu, H.; Walsh, D. M.; Selkoe, D. J. Large Soluble Oligomers of Amyloid $\beta$-Protein from Alzheimer Brain Are Far Less Neuroactive Than the Smaller Oligomers to Which They Dissociate. The Journal of Neuroscience 2017, 37, 152-163.

(25) Michaels, T. C. T.; Šarić, A.; Curk, S.; Bernfur, K.; Arosio, P.; Meisl, G.; Dear, A. J.; Cohen, S. I. A.; Dobson, C. M.; Vendruscolo, M.; Linse, S.; Knowles, T. P. J. Dynamics of oligomer populations formed during the aggregation of Alzheimer's A $\beta 42$ peptide. Nat. Chem. 2020, $12,445-451$.

(26) Ono, K.; Condron, M. M.; Teplow, D. B. Structure-neurotoxicity relationships of amyloid $\beta$-protein oligomers. Proc. Natl. Acad. Sci. U. S. A. 2009, 106, 14745.

(27) Zhou, Y.; Liu, J.; Zheng, T.; Tian, Y. Label-Free SERS Strategy for In Situ Monitoring and Real-Time Imaging of A $\beta$ Aggregation Process in Live Neurons and Brain Tissues. Anal. Chem. 2020, 92, 5910-5920.

(28) Brinet, D.; Kaffy, J.; Oukacine, F.; Glumm, S.; Ongeri, S.; Taverna, M. An improved capillary electrophoresis method for in vitro monitoring of the challenging early steps of $A \beta(1-$ 42) peptide oligomerization: Application to anti-Alzheimer's drug discovery. Electrophoresis 2014, 35, 3302-3309. (29) Brinet, D.; Gaie-Levrel, F.; Delatour, V.; Kaffy, J.; Ongeri, S.; Taverna, M. In vitro monitoring of amyloid $\beta$-peptide oligomerization by Electrospray differential mobility analysis: An alternative tool to evaluate Alzheimer's disease drug candidates. Talanta 2017, 165, 84-91. (30) Iuraşcu, M. I.; Cozma, C.; Tomczyk, N.; Rontree, J.; Desor, M.; Drescher, M.; Przybylski, M. Structural characterization of $\beta$-amyloid oligomer-aggregates by ion mobility mass spectrometry and electron spin resonance spectroscopy. Anal. Bioanal. Chem. 2009, 395, 25092519.

(31) Hu, J.; Zheng, Q. Applications of Mass Spectrometry in the Onset of Amyloid Fibril Formation: Focus on the Analysis of Early-Stage Oligomers. Frontiers in Chemistry 2020, 8, 324. (32) Bitan, G.; Kirkitadze, M. D.; Lomakin, A.; Vollers, S. S.; Benedek, G. B.; Teplow, D. B. Amyloid $\beta$-protein (A $\beta$ ) assembly: $\mathrm{A} \beta 40$ and $\mathrm{A} \beta 42$ oligomerize through distinct pathways. Proc. Natl. Acad. Sci. U. S. A. 2003, 100, 330-335. (33) Chamieh, J.; Cottet, H. In Colloid and Interface Science in Pharmaceutical Research and Development, Ohshima, H.; Makino, K., Eds.; Elsevier: Amsterdam, 2014, pp 173-192. 
(34) Taylor, G. The Dispersion of Matter in Turbulent Flow through a Pipe. Proc R Soc Lon Ser-

$600 \quad A$ 1954, 223, 446-468.

601 (35) Taylor, G. Dispersion of Soluble Matter in Solvent Flowing Slowly through a Tube. Proc $R$

602 Soc Lon Ser-A 1953, 219, 186-203.

603 (36) Cottet, H.; Biron, J. P.; Martin, M. Taylor Dispersion Analysis of Mixtures. Anal. Chem.

$6042007,79,9066-9073$.

605 (37) Bello, M. S.; Rezzonico, R.; Righetti, P. G. Use of Taylor-Aris Dispersion for Measurement

606 of a Solute Diffusion Coefficient in Thin Capillaries. Science 1994, 266, 773-776.

607 (38) Sharma, U.; Gleason, N. J.; Carbeck, J. D. Diffusivity of Solutes Measured in Glass

608 Capillaries Using Taylor's Analysis of Dispersion and a Commercial CE Instrument. Anal.

609 Chem. 2005, 77, 806-813.

610 (39) Cottet, H.; Martin, M.; Papillaud, A.; Souaï, E.; Collet, H.; Commeyras, A. Determination

Biomacromolecules 2007, 8, 3235-3243.

(40) d'Orlyé, F.; Varenne, A.; Gareil, P. Determination of nanoparticle diffusion coefficients by

Taylor dispersion analysis using a capillary electrophoresis instrument. J. Chromatogr. A 2008, 1204, 226-232.

(41) Chamieh, J.; Merdassi, H.; Rossi, J.-C.; Jannin, V.; Demarne, F.; Cottet, H. Size characterization of lipid-based self-emulsifying pharmaceutical excipients during lipolysis using Taylor dispersion analysis with fluorescence detection. Int. J. Pharm. 2018, 537, 94-101. (42) Urban, D. A.; Milosevic, A. M.; Bossert, D.; Crippa, F.; Moore, T. L.; Geers, C.; Balog, S.; Rothen-Rutishauser, B.; Petri-Fink, A. Taylor Dispersion of Inorganic Nanoparticles and Comparison to Dynamic Light Scattering and Transmission Electron Microscopy. Colloid and Interface Science Communications 2018, 22, 29-33.

(43) Pedersen, M. E.; Østergaard, J.; Jensen, H. Flow-Induced Dispersion Analysis (FIDA) for Protein Quantification and Characterization. Methods Mol. Biol. 2019, 1972, 109-123.

(44) Verpillot, R.; Otto, M.; Klafki, H.; Taverna, M. Simultaneous analysis by capillary electrophoresis of five amyloid peptides as potential biomarkers of Alzheimer's disease. $J$. Chromatogr. A 2008, 1214, 157-164.

(45) Botz, A.; Gasparik, V.; Devillers, E.; Hoffmann, A. R. F.; Caillon, L.; Chelain, E.; Lequin, O.; Brigaud, T.; Khemtemourian, L. (R)- $\alpha$-trifluoromethylalanine containing short peptide in the inhibition of amyloid peptide fibrillation. Peptide Science 2015, 104, 601-610.

(46) Provencher, S. W. CONTIN: A general purpose constrained regularization program for inverting noisy linear algebraic and integral equations. Comput. Phys. Commun. 1982, 27, 229242.

(47) Provencher, S. W. A constrained regularization method for inverting data represented by linear algebraic or integral equations. Comput. Phys. Commun. 1982, 27, 213-227. (48) Ortega, A.; Amorós, D.; García de la Torre, J. Prediction of Hydrodynamic and Other Solution Properties of Rigid Proteins from Atomic- and Residue-Level Models. Biophys. J. 2011, 101, 892-898.

(49) Naiki, H.; Higuchi, K.; Hosokawa, M.; Takeda, T. Fluorometric determination of amyloid fibrils in vitro using the fluorescent dye, thioflavine T. Anal. Biochem. 1989, 177, 244-249. (50) Chamieh, J.; Leclercq, L.; Martin, M.; Slaoui, S.; Jensen, H.; Østergaard, J.; Cottet, H. Limits in Size of Taylor Dispersion Analysis: Representation of the Different Hydrodynamic Regimes and Application to the Size-Characterization of Cubosomes. Anal. Chem. 2017, 89, 13487-13493. 
(51) Cottet, H.; Biron, J. P.; Martin, M. On the optimization of operating conditions for Taylor dispersion analysis of mixtures. Analyst 2014, 139, 3552-3562.

(52) Zheng, J.; Yeung, E. S. Mechanism of Microbial Aggregation during Capillary Electrophoresis. Anal. Chem. 2003, 75, 818-824.

(53) Schmidt, M.; Sachse, C.; Richter, W.; Xu, C.; Fändrich, M.; Grigorieff, N. Comparison of Alzheimer $\mathrm{A} \beta(1-40)$ and $\mathrm{A} \beta(1-42)$ amyloid fibrils reveals similar protofilament structures.

Proc. Natl. Acad. Sci. U. S. A. 2009, 106, 19813-19818.

(54) Sachse, C.; Fändrich, M.; Grigorieff, N. Paired $\beta$-sheet structure of an A $\beta(1-40)$ amyloid fibril revealed by electron microscopy. Proc. Natl. Acad. Sci. U. S. A. 2008, 105, 7462-7466. (55) Yusko, E. C.; Prangkio, P.; Sept, D.; Rollings, R. C.; Li, J.; Mayer, M. Single-Particle Characterization of A $\beta$ Oligomers in Solution. ACS Nano 2012, 6, 5909-5919.

(56) Cipelletti, L.; Biron, J.-P.; Martin, M.; Cottet, H. Measuring Arbitrary Diffusion Coefficient Distributions of Nano-Objects by Taylor Dispersion Analysis. Anal. Chem. 2015, 87, 8489-8496. (57) Arosio, P.; Knowles, T. P. J.; Linse, S. On the lag phase in amyloid fibril formation. PCCP 2015, 17, 7606-7618.

(58) Chen, Y.-R.; Glabe, C. G. Distinct Early Folding and Aggregation Properties of Alzheimer Amyloid- $\beta$ Peptides A $\beta 40$ and A $\beta 42$. J. Biol. Chem. 2006, 281, 24414-24422.

(59) Economou, N. J.; Giammona, M. J.; Do, T. D.; Zheng, X.; Teplow, D. B.; Buratto, S. K.; Bowers, M. T. Amyloid $\beta$-Protein Assembly and Alzheimer's Disease: Dodecamers of A $\beta 42$, but Not of A $\beta 40$, Seed Fibril Formation. J. Am. Chem. Soc. 2016, 138, 1772-1775.

(60) Fu, Z.; Aucoin, D.; Davis, J.; Van Nostrand, W. E.; Smith, S. O. Mechanism of Nucleated Conformational Conversion of A $\beta 42$. Biochemistry 2015, 54, 4197-4207.

(61) Bitan, G.; Lomakin, A.; Teplow, D. B. Amyloid $\beta$-Protein Oligomerization. J. Biol. Chem. 2001, 276, 35176-35184.

(62) Heyman, H. M.; Zhang, X.; Tang, K.; Baker, E. S.; Metz, T. O. In Encyclopedia of Spectroscopy and Spectrometry (Third Edition), Lindon, J. C.; Tranter, G. E.; Koppenaal, D. W., Eds.; Academic Press: Oxford, 2017, pp 376-384.

(63) Hawe, A.; Hulse, W.; Jiskoot, W.; Forbes, R. Taylor Dispersion Analysis Compared to Dynamic Light Scattering for the Size Analysis of Therapeutic Peptides and Proteins and Their Aggregates. Pharm. Res. 2011, 28, 2302-2310.

(64) Tomaselli, S.; Esposito, V.; Vangone, P.; van Nuland, N. A. J.; Bonvin, A. M. J. J.; Guerrini, R.; Tancredi, T.; Temussi, P. A.; Picone, D. The $\alpha$-to- $\beta$ Conformational Transition of Alzheimer's A $\beta-(1-42)$ Peptide in Aqueous Media is Reversible: A Step by Step Conformational Analysis Suggests the Location of $\beta$ Conformation Seeding. Chembiochem 2006, 7, 257-267. (65) Tran, L.; Basdevant, N.; Prévost, C.; Ha-Duong, T. Structure of ring-shaped A $\beta 42$ oligomers determined by conformational selection. Sci. Rep. 2016, 6, 21429. (66) Colvin, M. T.; Silvers, R.; Ni, Q. Z.; Can, T. V.; Sergeyev, I.; Rosay, M.; Donovan, K. J.; Michael, B.; Wall, J.; Linse, S.; Griffin, R. G. Atomic Resolution Structure of Monomorphic Aß42 Amyloid Fibrils. J. Am. Chem. Soc. 2016, 138, 9663-9674.

(67) Goddard, T. D.; Huang, C. C.; Meng, E. C.; Pettersen, E. F.; Couch, G. S.; Morris, J. H.; Ferrin, T. E. UCSF ChimeraX: Meeting modern challenges in visualization and analysis. Protein Sci. 2018, 27, 14-25.

(68) Lührs, T.; Ritter, C.; Adrian, M.; Riek-Loher, D.; Bohrmann, B.; Döbeli, H.; Schubert, D.; Riek, R. 3D structure of Alzheimer's amyloid- $\beta(1-42)$ fibrils. Proc. Natl. Acad. Sci. U. S. A. 2005, 102, 17342-17347. 
(69) Schmidt, M.; Rohou, A.; Lasker, K.; Yadav, J. K.; Schiene-Fischer, C.; Fändrich, M.; Grigorieff, N. Peptide dimer structure in an A $\beta(1-42)$ fibril visualized with cryo-EM. Proc. Natl.

692 Acad. Sci. U. S. A. 2015, 112, 11858-11863.

693 (70) Wälti, M. A.; Ravotti, F.; Arai, H.; Glabe, C. G.; Wall, J. S.; Böckmann, A.; Güntert, P.; Meier, B. H.; Riek, R. Atomic-resolution structure of a disease-relevant A $\beta(1-42)$ amyloid fibril. Proc. Natl. Acad. Sci. U. S. A. 2016, 113, E4976. (71) Kreutzer, A. G.; Hamza, I. L.; Spencer, R. K.; Nowick, J. S. X-ray Crystallographic Structures of a Trimer, Dodecamer, and Annular Pore Formed by an A $\beta 17-36 \beta$-Hairpin. J. Am. Chem. Soc. 2016, 138, 4634-4642.

(72) Ciudad, S.; Puig, E.; Botzanowski, T.; Meigooni, M.; Arango, A. S.; Do, J.; Mayzel, M.;

Bayoumi, M.; Chaignepain, S.; Maglia, G.; Cianferani, S.; Orekhov, V.; Tajkhorshid, E.; Bardiaux, B.; Carulla, N. A $\beta(1-42)$ tetramer and octamer structures reveal edge conductivity pores as a mechanism for membrane damage. Nature Communications 2020, 11, 3014. (73) Xiao, Y.; Ma, B.; McElheny, D.; Parthasarathy, S.; Long, F.; Hoshi, M.; Nussinov, R.; Ishii, Y. A $\beta(1-42)$ fibril structure illuminates self-recognition and replication of amyloid in Alzheimer's disease. Nat. Struct. Mol. Biol. 2015, 22, 499-505.

(74) Cohen, S. I. A.; Linse, S.; Luheshi, L. M.; Hellstrand, E.; White, D. A.; Rajah, L.; Otzen, D. E.; Vendruscolo, M.; Dobson, C. M.; Knowles, T. P. J. Proliferation of amyloid- $\beta 42$ aggregates occurs through a secondary nucleation mechanism. Proc. Natl. Acad. Sci. U. S. A. 2013, 110, 9758-9763.

(75) Cohen, S. I. A.; Vendruscolo, M.; Welland, M. E.; Dobson, C. M.; Terentjev, E. M.; Knowles, T. P. J. Nucleated polymerization with secondary pathways. I. Time evolution of the principal moments. J. Chem. Phys. 2011, 135, 065105.

(76) Knowles, T. P. J.; Waudby, C. A.; Devlin, G. L.; Cohen, S. I. A.; Aguzzi, A.; Vendruscolo, M.; Terentjev, E. M.; Welland, M. E.; Dobson, C. M. An Analytical Solution to the Kinetics of Breakable Filament Assembly. Science 2009, 326, 1533-1537.

(77) Lee, C.-T.; Terentjev, E. M. Mechanisms and rates of nucleation of amyloid fibrils. J. Chem. Phys. 2017, 147, 105103.

(78) Srivastava, A. K.; Pittman, J. M.; Zerweck, J.; Venkata, B. S.; Moore, P. C.; Sachleben, J. R.; Meredith, S. C. $\beta$-Amyloid aggregation and heterogeneous nucleation. Protein Sci. 2019, 28, 1567-1581.

(79) Shea, D.; Hsu, C.-C.; Bi, T. M.; Paranjapye, N.; Childers, M. C.; Cochran, J.; Tomberlin, C. P.; Wang, L.; Paris, D.; Zonderman, J.; Varani, G.; Link, C. D.; Mullan, M.; Daggett, V. $\alpha$-Sheet secondary structure in amyloid $\beta$-peptide drives aggregation and toxicity in Alzheimer's disease. Proc. Natl. Acad. Sci. U. S. A. 2019, 116, 8895-8900.

(80) Ahmed, M.; Davis, J.; Aucoin, D.; Sato, T.; Ahuja, S.; Aimoto, S.; Elliott, J. I.; Van Nostrand, W. E.; Smith, S. O. Structural conversion of neurotoxic amyloid- $\beta 1-42$ oligomers to fibrils. Nat. Struct. Mol. Biol. 2010, 17, 561-567.

(81) Ghosh, P.; Vaidya, A.; Kumar, A.; Rangachari, V. Determination of critical nucleation number for a single nucleation amyloid- $\beta$ aggregation model. Math. Biosci. 2016, 273, 70-79. (82) Gremer, L.; Schölzel, D.; Schenk, C.; Reinartz, E.; Labahn, J.; Ravelli, R. B. G.; Tusche, M.; Lopez-Iglesias, C.; Hoyer, W.; Heise, H.; Willbold, D.; Schröder, G. F. Fibril structure of amyloid- $\beta(1-42)$ by cryo-electron microscopy. Science 2017, 358, 116-119.

(83) Novo, M.; Freire, S.; Al-Soufi, W. Critical aggregation concentration for the formation of early Amyloid- $\beta$ (1-42) oligomers. Sci. Rep. 2018, 8, 1783. 
(84) Mastrangelo, I. A.; Ahmed, M.; Sato, T.; Liu, W.; Wang, C.; Hough, P.; Smith, S. O. Highresolution Atomic Force Microscopy of Soluble A $\beta 42$ Oligomers. J. Mol. Biol. 2006, 358, 106119.

(85) Nirmalraj, P. N.; List, J.; Battacharya, S.; Howe, G.; Xu, L.; Thompson, D.; Mayer, M. Complete aggregation pathway of amyloid beta (1-40) and (1-42) resolved on an atomically clean interface. Sci Adv 2020, 6, eaaz6014. (86) Lacor, P. N.; Buniel, M. C.; Furlow, P. W.; Sanz Clemente, A.; Velasco, P. T.; Wood, M.; Viola, K. L.; Klein, W. L. A $\beta$ Oligomer-Induced Aberrations in Synapse Composition, Shape, and Density Provide a Molecular Basis for Loss of Connectivity in Alzheimer\&\#039;s Disease. The Journal of Neuroscience 2007, 27, 796. (87) Velasco, P. T.; Heffern, M. C.; Sebollela, A.; Popova, I. A.; Lacor, P. N.; Lee, K. B.; Sun, X.; Tiano, B. N.; Viola, K. L.; Eckermann, A. L.; Meade, T. J.; Klein, W. L. Synapse-Binding Subpopulations of A $\beta$ Oligomers Sensitive to Peptide Assembly Blockers and scFv Antibodies. ACS Chem. Neurosci. 2012, 3, 972-981.

(88) Lesné, S.; Koh, M. T.; Kotilinek, L.; Kayed, R.; Glabe, C. G.; Yang, A.; Gallagher, M.; Ashe, K. H. A specific amyloid- $\beta$ protein assembly in the brain impairs memory. Nature 2006, $440,352-357$. 
755 for Table of Contents only

756

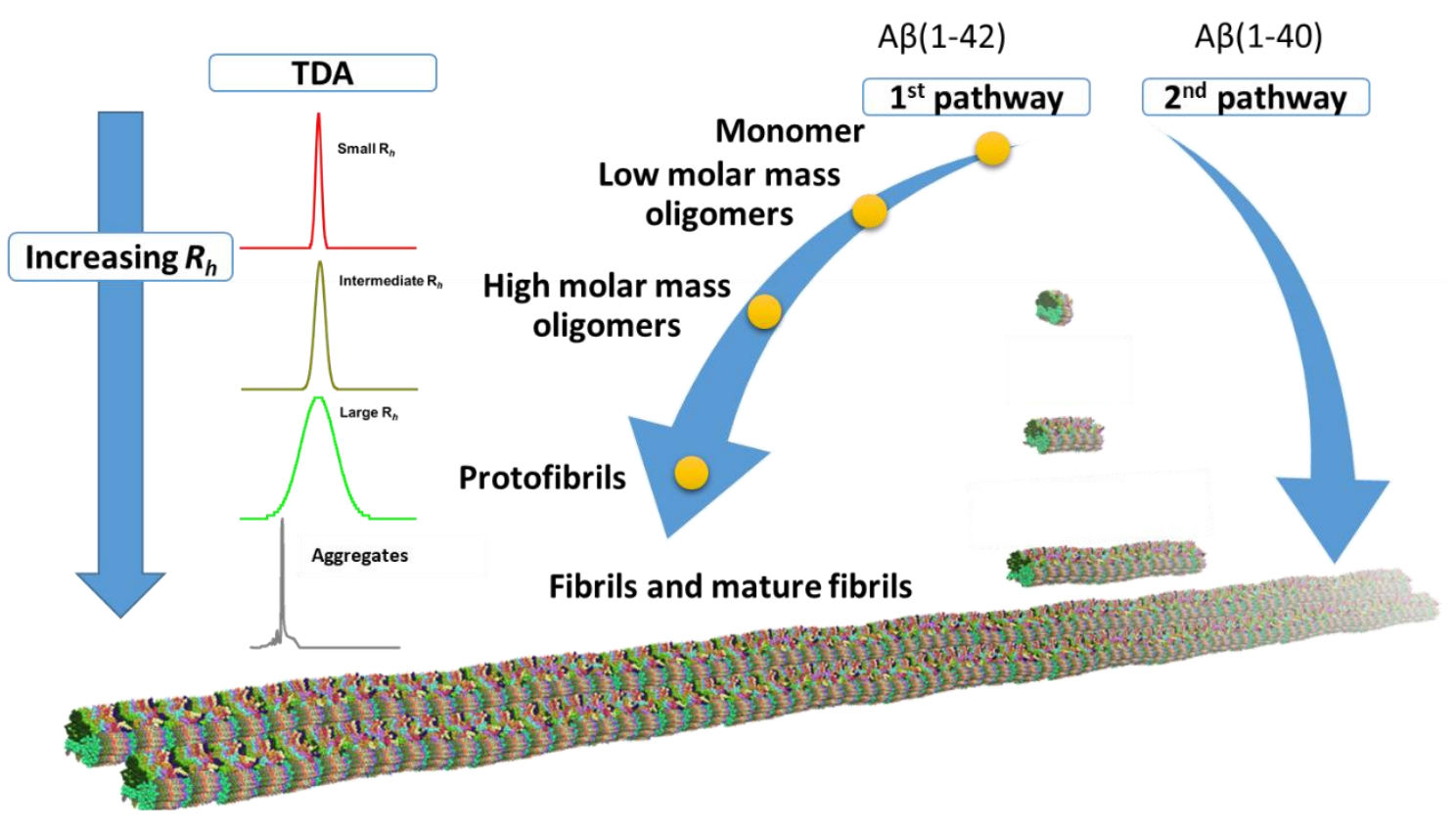

757 
